\title{
Characterization of Staufen1 ribonucleoproteins by mass spectrometry and biochemical analyses reveal the presence of diverse host proteins associated with human immunodeficiency virus type 1
}

\author{
Miroslav P. Milev ${ }^{1,2}$, Mukunthan Ravichandran ${ }^{1,2}$, Morgan F. Khan $^{3}$, David C. Schriemer $^{3}$ and \\ Andrew J. Mouland ${ }^{1,2,4}$ *
}

${ }^{1}$ HIV-1 Trafficking Laboratory, Lady Davis Institute at the Jewish General Hospital, Montréal, QC, Canada

${ }^{2}$ Division of Experimental Medicine, Department of Medicine, McGill University, Montreal, OC, Canada

${ }^{3}$ Department of Biochemistry and Molecular Biology, University of Calgary, Calgary, AB, Canada

${ }^{4}$ Department of Microbiology and Immunology, McGill University, Montreal, QC, Canada

\section{Edited by:}

Kevin Coombs, University of

Manitoba, Canada

Reviewed by:

Chiaho Shih, Academia Sinica, Taiwan

Mikako Fujita, Kumamoto University,

Japan

${ }^{*}$ Correspondence:

Andrew J. Mouland, Lady Davis

Institute at the Jewish General

Hospital and McGill University, 3755

Côte-Ste-Catherine Road, Montréal,

QC, Canada H3T 1 E2.

e-mail: andrew.mouland@mcgill.ca
The human immunodeficiency virus type 1 (HIV-1) unspliced, 9 kb genomic RNA (vRNA) is exported from the nucleus for the synthesis of viral structural proteins and enzymes ( $\mathrm{Gag}$ and $\mathrm{Gag} / \mathrm{Pol}$ ) and is then transported to sites of virus assembly where it is packaged into progeny virions. vRNA co-exists in the cytoplasm in the context of the HIV-1 ribonucleoprotein (RNP) that is currently defined by the presence of Gag and several host proteins including the double-stranded RNA-binding protein, Staufen1. In this study we isolated Staufen1 RNP complexes derived from HIV-1-expressing cells using tandem affinity purification and have identified multiple host protein components by mass spectrometry. Four viral proteins, including Gag, Gag/Pol, Env and Nef as well as $>200$ host proteins were identified in these RNPs. Moreover, HIV-1 induces both qualitative and quantitative differences in host protein content in these RNPs. $22 \%$ of Staufen1-associated factors are virion-associated suggesting that the RNP could be a vehicle to achieve this. In addition, we provide evidence on how HIV-1 modulates the composition of cytoplasmic Staufen1 RNPs. Biochemical fractionation by density gradient analyses revealed new facets on the assembly of Staufen1 RNPs. The assembly of dense Staufen1 RNPs that contain Gag and several host proteins were found to be entirely RNA-dependent but their assembly appeared to be independent of Gag expression. Gag-containing complexes fractionated into a lighter and another, more dense pool. Lastly, Staufen 1 depletion studies demonstrated that the previously characterized Staufen1 HIV-1-dependent RNPs are most likely aggregates of smaller RNPs that accumulate at juxtanuclear domains. The molecular characterization of Staufen 1 HIV-1 RNPs will offer important information on virus-host cell interactions and on the elucidation of the function of these RNPs for the transport of Gag and the fate of the unspliced vRNA in HIV-1-producing cells.

Keywords: Gag, genomic RNA, HIV-1, mass spectrometry, gradient centrifugation, ribonucleoprotein, Staufen1, virus-host interactions

\section{INTRODUCTION}

HIV-1 infection is characterized by a progressive depletion of $\mathrm{CD} 4+\mathrm{T}$ lymphocytes that makes patients susceptible to opportunistic diseases and ultimately leads to the development of acquired immunodeficiency syndrome (AIDS; Ho et al., 1995; Lindwasser et al., 2007). HIV-1 replication is divided into early and late events (Wang et al., 2000; Freed, 2001): the early events include virus entry, uncoating of the viral core that contains the vRNA, reverse transcription of vRNA to cDNA and finally, the integration of the resulting viral double-stranded DNA into host chromosomes. The later events include the transcription of the proviral genome to generate a primary transcript, the vRNA, its processing, maturation and nucleocytoplasmic export and also the synthesis of viral structural proteins, virus assembly and budding. Following transcription, the vRNA either remains unspliced or is spliced to generate more than 30 distinct mRNAs that are grouped into singly spliced, $4 \mathrm{~kb}$ mRNAs (encoding the auxiliary proteins Vif, Vpr, Vpu and the glycoprotein, Env) or into multiply spliced, $1.8 \mathrm{~kb}$ mRNA species (encoding the early viral regulatory proteins Tat, Rev and Nef; Arrigo et al., 1990; Schwartz et al., 1990; Purcell and Martin, 1993). The $1.8 \mathrm{~kb}$ RNAs are constitutively exported from the nucleus early following transcription, while the nuclear export of vRNA and the $4 \mathrm{~kb}$ species is dependent on the CRM1/Exportin1 export pathway (Yi et al., 2002). These events are well orchestrated, dynamic and depend on the activities of viral as well as select host cell proteins and machineries that are co-opted by the virus. 
The two largest viral mRNA species, which contain intronic sequences, are both exported from the nucleus and translated in the cytoplasm. While usually mRNAs with introns are tagged as aberrant since they are "incompletely spliced" and are degraded by cellular RNA quality control machineries (Doma and Parker, 2007), these viral mRNAs are quite stable (Mouland et al., 2002), and therefore likely evade this surveillance machinery by coopting host proteins involved in this process (Ajamian et al., 2008; Nathans et al., 2009). Furthermore, vRNA has an additional fate in that it can also be packaged into progeny virions (Butsch and Boris-Lawrie, 2002). This latter step is made possible by a selective interaction between vRNA and its gene product, the precursor Group specific antigen, pr55 $5^{\mathrm{Gag}}$ (termed Gag herein). Gag interacts with a packaging signal in the $5^{\prime} \mathrm{UTR}$ of vRNA for selection into assembling virions (Lever et al., 1989; Clever et al., 1995). Like other mRNAs, vRNA is likely transported through the cytoplasm in the context of an RNP (Wilhelm and Vale, 1993; Mouland et al., 2001; Lehmann et al., 2009). Indeed, mRNA-binding proteins such as Staufen1 associate closely with Gag to form the HIV-1 RNP that also incorporates vRNA, but none of the spliced HIV-1 RNAs (ChatelChaix et al., 2004; Cochrane et al., 2006). Moreover, recent work has demonstrated that HIV-1 RNPs that contain Staufen1 take advantage of endosomal machineries for intracellular trafficking (Lehmann et al., 2009; Molle et al., 2009). Nevertheless, these later events still remain one of the most understudied areas of HIV-1 biology.

Generally, like other cellular RNPs, the composition of cytosolic HIV-1 RNPs is plastic in nature such that proteins may engage in the nucleus, disengage and/or be acquired during transit from the nucleus to the cytoplasm and during the assembly of vRNA into viral particles. The composition of the HIV-1 RNP has not been completely characterized, however. Recent work supports the idea that vRNA interacts with Gag at juxtanuclear and cytoplasmic domains (Poole et al., 2005; Levesque et al., 2006) and considerable efforts are now being made to evaluate how HIV-1 co-opts factors following the nuclear export of the vRNA - a late step in HIV-1 replication that includes RNA transport, utilization (translation) and degradation (Cochrane et al., 2006; Lehmann et al., 2009; Molle et al., 2009; Kemler et al., 2010). The formation of the HIV-1 RNP is initially achieved by the binding of Gag via its nucleocapsid (NC) domain and the RNA packaging signal psi in the $5^{\prime}$-end of the vRNA. This early capture may govern the directed movement of vRNA along the cytoskeleton, to the translation apparatus, to sites of viral assembly and finally, into assembling viral particles. A number of host gene products, such as hnRNP A1, PSF/nsr54 and APOBEC3G associate with vRNA (Beriault et al., 2004; Khan et al., 2005). Furthermore, a limited set of host trans-acting proteins mediates trafficking by binding to specific cis-acting sequence elements in vRNA (Mouland et al., 2001; Levesque et al., 2006). While the stability and functionality of HIV-1 RNP is most probably a result of interactions between a few viral (i.e., Gag) and host cell proteins such as Staufen1 and Upf1 (Up-frameshift protein 1; Chatel-Chaix et al., 2004; Ajamian et al., 2008), the molecular composition of the HIV-1 RNP likely changes and is dictated by HIV-1, either by direct recruitment of, or by binding to host cell factors.
Staufen1 belongs to a growing family of the double-stranded RNA-binding proteins (dsRBPs) that includes protein kinase dsRNA dependent (PKR), the activator of PKR (PACT), TAR-RNA binding protein (TRBP) and RNA Helicase A (RHA, reviewed in (Fierro-Monti and Mathews, 2000; Saunders and Barber, 2003; Tian et al., 2004) and is a principal component of various RNPs that are engaged in the localization and trafficking of cellular mRNAs (Kiebler et al., 1999; Kiebler and DesGroseillers, 2000; Roegiers and Jan, 2000). Staufen1-containing high-molecular weight complexes ranging in size from 10-30 MDa appear as granules dispersed in the cytoplasm of eukaryotic cells. Several components are found in these complexes such as ribosomes, tubulin, actin, dynein, RHA, hnRNP U and nucleolin (Brendel et al., 2004; Villace et al., 2004). RNA-binding by Staufen1 regulates diverse classes of mammalian mRNAs that encode proteins with functions in different metabolic pathways and cellular physiological processes (Kim et al., 2007; Furic et al., 2008).

Our previous work demonstrated that Staufen 1 binds to both Gag as well as its vRNA substrate (while excluding all of the spliced HIV-1 RNA species), which likely drives the incorporation of Gag and vRNA into assembling virions through the formation of a HIV-1 RNP (Mouland et al., 2000; Chatel-Chaix et al., 2004). Furthermore, modulating the levels of Staufen1, by siRNAs and overexpression, perturbs HIV-1 assembly, including Gag multimerization and vRNA encapsidation, resulting in negative effects on viral infectivity (Mouland et al., 2000; Chatel-Chaix et al., 2004, 2007, 2008; Abrahamyan et al., 2010). Staufen1 also influences the anterograde trafficking of Gag. Both Staufen 1 and Gag were shown to associate in the cytoplasm and also at cholesterol-enriched lipid rafts, which are virus assembly domains (Milev et al., 2010).

Staufen 1 potentially may play similar roles in the replication of other retroviruses, such as, HIV-2 and MLV since it was found incorporated within them (Mouland et al., 2000). Importantly it does not associate with any tested DNA virus, including adenovirus, Epstein-Barr virus and human herpesvirus 6, supporting its preferential role in the biology of RNA viruses. In a yeast twohybrid screen and in co-immunoprecipitation (IP) experiments, Staufen 1 was identified as an interactive partner of the influenza A virus non-structural protein, NS1 (Falcon et al., 1999). Recent work demonstrated that Staufen 1 also associates to viral RNPs and viral RNAs in influenza virus-infected cells (de Lucas et al., 2010). Staufen 1 also associates with the $3^{\prime}$ UTR of HCV RNA, the sequence essential for the initiation of $(-)$ strand synthesis (Harris et al., 2006). Together with the numerous other cellular proteins found to interact with this region, Staufen 1 most probably also plays a role in HCV replication.

The aim of the work described here was to examine the composition of the Staufen1 RNP proteome and how it is modulated by HIV-1. To do this, Staufen1-binding proteins were purified using tandem affinity purification (TAP) in HIV-1-expressing cells and identified by mass spectrometry. Approximately 200 host proteins were identified using this strategy. The Staufen1 HIV-1 RNP that bound precursor Gag shared many proteins with cytosolic RNA trafficking RNPs. However, notable compositional differences of the Staufen 1 RNPs were induced by HIV-1. Furthermore, $\sim 22 \%$ of the identified proteins are found in isolated HIV-1 particles. Biochemical and imaging analyses confirmed many of these 
associations. Biochemical fractionation of cellular RNPs revealed further characteristics of the Staufen 1 RNPs that are assembled in HIV-1-producing cells. Our results provide a comprehensive view on the composition of Staufen1-containing HIV-1 RNPs and their functional importance that likely resides in the fate of the vRNA.

\section{MATERIALS AND METHODS CELLS AND CELL LINES}

Human embryonic kidney 293T cells HeLa, and Jurkat T cells were maintained at $37^{\circ} \mathrm{C}$ in Dulbecco's modified Eagle's or RPMI-1640 medium supplemented with $10 \%$ decomplemented fetal bovine serum (FBS) and $100 \mathrm{U} / \mathrm{ml}$ penicillin, $100 \mathrm{mg} / \mathrm{ml}$ streptomycin (Invitrogen). Stable TAP and Staufen1-TAP neomycin-resistant cell lines were generated in 293T and Jurkat T cells. Briefly, 293T cell were plated in $60 \mathrm{~mm}$ dishes and Jurkat T cells in $25 \mathrm{~cm}^{2}$ flasks. The following day these were transfected with 2 and $4 \mu \mathrm{g}$ plasmid DNA, respectively, using Lipofectamine 2000 according to the protocol provided by the manufacturer (Invitrogen). $24 \mathrm{~h}$ post-transfection, $600 \mu \mathrm{g} / \mathrm{ml} \mathrm{G} 418$ (Invitrogen) was added to the medium for selection. The cell cultures were maintained at $90 \%$ confluence and subsequently, sub-cultured at lower densities. Resistant clones were isolated 14 days following selection. Tissue culture medium was removed from the plates, and cells were washed with sterile PBS. To pick colonies, sterile $3 \mathrm{~mm}$ cloning disks were dipped in trypsin solution and placed on colonies for $30 \mathrm{~s}$. The colonies adhered to the cloning disks and were transferred to 24-well dishes. When the cells reached pre-confluence, they were transferred to 6-well plates. For suspension Jurkat T cells, the procedure for isolation of stable clones differed as follows: cells were maintained in RPMI-1640 with $600 \mu \mathrm{g} / \mathrm{ml} \mathrm{G418}$ for 14 days and then were serially diluted and transferred in 24-well dishes for expansion. The surviving stable lines exhibited various expression levels of the TAP tagged Staufen 1 as assessed by SDSPAGE and western blotting. Staufen1-TAP expression levels were constant for each clone and were stable for at least 20 subsequent passages.

\section{TRANSIENT TRANSFECTIONS}

For affinity purification experiments, transfection of control TAP and Staufen1-TAP stable cell lines with proviral DNA, pNL4-3, was carried out in $150 \mathrm{~cm}^{2}$ flasks (Nunc). The cells were plated at $5 \times 10^{6}$ per flask for $24 \mathrm{~h}$ before transfection. $20 \mu \mathrm{g}$ of plasmid and $50 \mu \mathrm{l}$ Lipofectamine per flask were added, cells were incubated for $20 \mathrm{~min}$ and then mixed with tissue culture medium. For IP analyses, HeLa cells were transfected with corresponding amounts of plasmid DNA and cell lysates were prepared as described previously (Mouland et al., 2000; Chatel-Chaix et al., 2004). The overexpression of IMP1 (in the context of IMP1-VenC fusion protein) was performed in both HeLa and 293T cells. Transfection efficiencies were greater than $65 \%$ in all experiments (range 65-80\%).

Staufen 1-HA, pNL4-3 and pNL4-XX and transfection of HeLa cells were described previously (Mouland et al., 2000; ChatelChaix et al., 2004; Ajamian et al., 2008). For sucrose gradient fractionation experiments, transfection of proviral DNA, pNL4-3 was carried out in $75 \mathrm{~cm}^{2}$ flasks (Nunc). The cells were plated at $3 \times 10^{6}$ per flask for $12 \mathrm{~h}$ before transfection. Transfection efficiencies were greater than 70\% in all experiments (range 65$80 \%$ ). For RNase A treatments, cell lysates were incubated for $30 \mathrm{~min}$ at $4^{\circ} \mathrm{C}$ with RNase T1 at $1 \mathrm{U} / \mathrm{mL}$. HeLa cells were transfected with either non-silencing siRNA (siNS) or Staufen 1 siRNA (siStaufen1) at a final concentration of $10 \mathrm{nM}$. siRNA transfections were performed with lipofectamine 2000. Thirty-six hours later, the cells were washed with ice cold PBS and lysed in XB buffer for subcellular fractionation in sucrose gradients (see below; Chatel-Chaix et al., 2004).

\section{TANDEM AFFINITY PURIFICATION AND WESTERN BLOTTING}

The purification of Staufen 1 complexes was adapted using the TAP protocols as described previously (Puig et al., 2001; Villace et al., 2004). Briefly, after transfection, cells were lysed in buffer $(50 \mathrm{mM}$ Tris- $\mathrm{HCl} \mathrm{pH}$ 7.5, 5 mM EDTA, $100 \mathrm{mM} \mathrm{NaCl}, 1 \mathrm{mM}$ DTT, 0.5\% NP-40) and complete protease inhibitor cocktail (Roche). Cell extracts were centrifuged at $4{ }^{\circ} \mathrm{C}$ for $5 \mathrm{~min}$ at $5000 \mathrm{rpm}$ and the recovered supernatants were centrifuged for $15 \mathrm{~min}$ at $14,000 \times \mathrm{g}$. The lysates were stored at $-20^{\circ} \mathrm{C}$. In the first affinity purification step, 20-75 mg cell lysates were applied to IgG Sepharose six Fast Flow beads (Amersham Biosciences; at a ratio of $5 \mu \mathrm{l}$ beads per $1 \mathrm{mg}$ protein). The resin was prepared according to the manufacturer's protocol. After overnight incubation at $4^{\circ} \mathrm{C}$, the IgG resin was washed 10 times with 10 volumes of IPP-150 buffer

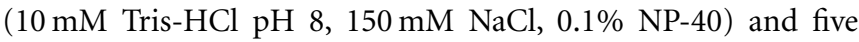
times with 10 volumes of TEV cleavage buffer - TCB $(10 \mathrm{mM}$ Tris- $\mathrm{HCl} \mathrm{pH} 8,150 \mathrm{mM} \mathrm{NaCl}, 0.1 \%$ NP-40, $0.5 \mathrm{mM}$ EDTA). $20 \mathrm{U}$ of ActivTEV - Tobacco Etch Virus protease (Invitrogen, Carlsbad, USA) in TCB $(300 \mu \mathrm{l})$ was then added to the resin and rotated for $2 \mathrm{~h}$ at room temperature in order to release the complexes bound to the resin $(100 \mu \mathrm{l})$. In the second affinity purification step, the supernatant after TEV cleavage was adjusted with $\mathrm{CaCl}_{2}$ to a $2 \mathrm{mM}$ final concentration and incubated overnight with $60 \mu$ l Stratagene Calmodulin-affinity resin (Agilent Technologies, Cedar Creek, USA). The resin was then washed three times with 10 volumes of Calmodulin-binding buffer, CBB (10 mM beta-mercaptoethanol, $10 \mathrm{mM}$ Tris- $\mathrm{HCl} \mathrm{pH} 8,150 \mathrm{mM} \mathrm{NaCl}, 0.1 \%$ NP-40, 1 mM imidazol, $1 \mathrm{mM} \mathrm{MgOAc}, 2 \mathrm{mM} \mathrm{CaCl}_{2}$ ) and two times with 10 volumes of Calmodulin-rinsing buffer, CRB (50 mM ammonium bicarbonate $\mathrm{pH} 8.0,75 \mathrm{mM} \mathrm{NaCl}, 1 \mathrm{mM} \mathrm{MgOAc}, 1 \mathrm{mM}$ imidazol, $2 \mathrm{mM}$ $\mathrm{CaCl}_{2}$ ). For the elution of complexes, the beads were resuspended and incubated for several minutes with $\sim 100 \mu \mathrm{l}$ of Calmodulinelution buffer, CEB (50 mM ammonium bicarbonate, $15-25 \mathrm{mM}$ EGTA). Western blotting of input cell lysates and affinity-purified eluates was performed by standard procedures (Abrahamyan et al., 2010) using several of the primary antisera described below. TAP and western blotting results are representative of $>5$ independent experiments.

\section{COOMASSIE BLUE STAINING AND GEL SLICE EXCISION}

For mass spectrometry analysis, the eluates were fractionated on 4-12\% SDS-PAGE and the gels were then subjected to three $5 \mathrm{~min}$ washes in $300 \mathrm{ml}$ double distillated water $\left(\mathrm{ddH}_{2} \mathrm{O}\right)$ and stained with $100 \mathrm{ml}$ Bio-Safe Coomassie stain (Bio-Rad) for $60 \mathrm{~min}$ followed by destaining. In total, 23 gel slices from each experiment (St-TAP or St-TAP + HIV-1) were excised, placed in a prewashed, low-retention $1.5 \mathrm{ml}$ snap-cap tubes for subsequent in 
gel digestion and liquid chromatography and mass spectrometry (LC-MS) analysis.

\section{IN GEL DESTAINING AND DIGESTION}

Gel bands were diced into $\sim 1 \mathrm{~mm}^{2}$ pieces and rinsed once with $200 \mu \mathrm{l}$ HPLC-grade water, twice with $200 \mu \mathrm{l} 25 \mathrm{mM}$ ammonium bicarbonate in $50 \%(\mathrm{v} / \mathrm{v})$ acetonitrile, followed by $100 \mu \mathrm{l}$ acetonitrile to dehydrate the gel plugs, which were then lyophilized. The dry gel plugs were rehydrated in 5-7 $\mu \mathrm{l}$ of $25 \mathrm{mM}$ ammoniumbicarbonate, $\mathrm{pH} 8.0$, containing $12.5 \mathrm{ng} / \mu \mathrm{l}$ trypsin. After rehydration, an additional $30 \mu \mathrm{l}$ of $25 \mathrm{mM}$ ammonium bicarbonate was added and the gel plugs were incubated overnight at $37^{\circ} \mathrm{C}$. Peptides were extracted from gel plugs by two rounds of incubation with $50 \mu \mathrm{l}$ of $1 \%$ formic acid in $50 \%$ acetonitrile. The pooled extracts were reduced to dryness and reconstituted in mobile phase A for reversed phase chromatography.

\section{MASS SPECTROMETRY}

Digests were analyzed using an Agilent 1100 LC-Ion-Trap-XCTUltra system (Agilent Technologies, Santa Clara, CA, USA) fitted with an integrated fluidics cartridge for peptide capture, separation, and nano-spraying (HPLC Chip). Injected samples were trapped and desalted on a pre-column channel (40 nl volume; Zorbax $300 \mathrm{SB}-\mathrm{C}_{18}$ ) for $5 \mathrm{~min}$ with mobile phase $\mathrm{A}$ ( $3 \%$ acetonitrile, $0.2 \%$ formic acid) delivered by an auxiliary pump at $4 \mu \mathrm{l} / \mathrm{min}$. The peptides were then reverse-eluted from the trapping column and separated on the analytical column (150 mm length; Zorbax $300 \mathrm{SB}-\mathrm{C}_{18}$ ) at $0.3 \mu \mathrm{l} / \mathrm{min}$. Peptides were eluted using a $5-70 \%$ gradient in mobile phase B ( $97 \%$ acetonitrile, $0.2 \%$ formic acid) over $45 \mathrm{~min}$. MS/MS spectra were collected by data-dependent acquisition, with parent ion scans of $8,100 \mathrm{Th} / \mathrm{s}$ over $\mathrm{m} / z$ 300-2,000 and MS/MS scans at the same rate over $m / z$ 100-2,200. Peak-list data were extracted from these files by DataAnalysis software for the 6300 series ion trap, v3.4 (build 175). Mascot v2.2 (MatrixScience, Boston, MA, USA) was used to search the MS/MS data using the following parameters: 1.6 Da precursor ion mass tolerance, $0.8 \mathrm{Da}$ fragment ion mass tolerance, one potential missed cleavage, and oxidized methionine as a variable modification. NCBI nr 2008.01.03 (5,824,077 sequences) was searched, with a restriction to "other viruses" and humans. Mass spectrometry analyses on isolated TAP eluates were reproduced at least two times in independent experiments.

\section{ANTIBODIES AND REAGENTS}

Mouse anti-Staufen1, anti-UPF (1, 2 and 3), anti-RHA and antiAUF1 antibodies were provided by Luc DesGroseillers (Université de Montréal), Jens-Lykke Andersen (University of California), Juan Ortin (Centro Nacional de Biotecnologia, Madrid, Spain) and William Rigby (Dartmouth University, NH, USA), respectively (Villace et al., 2004; Ajamian et al., 2008; Abrahamyan et al., 2010). Rabbit anti-IMP1 and anti-ABCE1 antibodies were generous gifts from Finn Nielsen (University of Copenhagen) and from Jaisri Lingappa (University of Washington; Zimmerman et al., 2002; Milev et al., 2010), respectively. Mouse anti-Tsg101 and antiL7 antibodies were purchased from Novus Biologicals (Littleton, USA), anti-eF1 $\alpha$, anti-TDP-43 and anti-CRM1 were purchased from Upstate (Millipore), ProteinTech Group (Chicago, USA) and
Santa Cruz (California, USA), respectively; rabbit anti-p17 and sheep anti-gp120 were obtained from the NIH (Abrahamyan et al., 2010). For all immunofluorescence (IF) experiments, secondary AlexaFluor anti-mouse, anti-rabbit or anti-sheep conjugated antibodies were used (Invitrogen) as previously described (Milev et al., 2010).

\section{IMMUNOFLUORESCENCE, FISH AND CONFOCAL MICROSCOPY}

At $24-48 \mathrm{~h}$ after transfection, cells were washed two times with $1 \times$ PBS and fixed in 4\% PFA for $20 \mathrm{~min}$, washed two times with $1 \times$ PBS and treated with $0.2 \%$ Triton X-100 for $10 \mathrm{~min}$. IF and FISH were performed essentially as previously described (Lehmann et al., 2009; Milev et al., 2010; Vyboh et al., 2012). Cells were then incubated for $10 \mathrm{~min}$ with $0.1 \mathrm{M}$ glycine, washed and blocked for $30 \mathrm{~min}$ in $1 \times$ BSA (Roche Applied Science, Germany). The primary antibody was incubated for $1.5 \mathrm{~h}$ at room temperature. Cells were washed $2 \times$ with PBS and subsequently incubated with secondary antibody for $30 \mathrm{~min}$. After this step the glass coverslips were washed $2 \times$ with PBS, mounted on slides and visualized with a Carl Zeiss Pascal LSM5 laser scanning confocal microscope (Carl Zeiss, Germany).

\section{EXPRESSION VECTORS}

Plasmids pcDNASt-TAP and pcDNA-TAP were constructed as previously described (Villace et al., 2004). Proviral DNA, pNL4-3 was described in previous work (Adachi et al., 1986; Chatel-Chaix et al., 2004). pNL4-XX, a proviral DNA derived from pNL4-3, harbors two mutations in the gag open reading frame to prevent Gag and Gag/Pol synthesis, was described elsewhere (Poon et al., 2002; Abrahamyan et al., 2010). Constructs expressing Staufen1HA, pGL3-IMP1-VenusC and pGL3-MS2-Venus (full length) were described previously (Milev et al., 2010). pCMV-Gag-RRE was described earlier (Lingappa et al., 2006).

\section{SUBCELLULAR FRACTIONATION}

Following transfection, cells were washed with ice cold PBS, homogenized in an equal volume of XB Buffer $(20 \mathrm{mM}$ HEPES $\mathrm{pH}$ 7.9, $1.5 \mathrm{mM} \mathrm{MgCl}_{2}, 0.5 \mathrm{mM}$ DTT, protease inhibitor cocktail). The homogenate was centrifuged for $10 \mathrm{~min}$ at 5,000 rpm to remove the insoluble material. The supernatant ( $1 \mathrm{mg}$ total protein) was

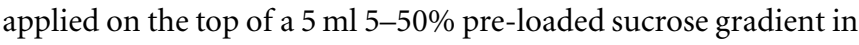
XB buffer, as described (Yoon and Mowry, 2004). Lysates were separated by centrifugation at 44,000 rpm for $2 \mathrm{~h}$ in SW55i beckman rotor at $17^{\circ} \mathrm{C} .18-20250 \mu \mathrm{l}$ fractions were collected and resolved by SDS-PAGE or processed for slot blot analyses.

\section{RNA SLOT BLOT ANALYSES}

In order to evaluate vRNA fractionation in sucrose gradient fractions, an aliquot of each eluate was mixed 1:3 with GTC and FFM solution (10× OPS buffer, 37\% Formaldehyde, 99\% Formamide) and heated at $65^{\circ} \mathrm{C}$ for $15 \mathrm{~min}$ and transferred to $0.45 \mu \mathrm{m}$ nylon membrane by intermittent suction for slot blot analyses using a Gibco/BRL slot blot apparatus. A ${ }^{[32]} \mathrm{P}$-labeled cDNA probe to the HIV-1 5' gag coding region to recognize the vRNA only was prepared using random prime labeling kit, as described (Yao et al., 1998; Mouland et al., 2000). 


\section{RESULTS \\ GENERATION OF STAUFEN1-TAP AND CONTROL TAP STABLE CELL LINES}

Tandem affinity purification is a powerful method for the specific isolation of protein complexes under native conditions. In order to characterize Staufen1 HIV-1 RNP complexes and to determine Staufen1-binding partners, we generated neomycin-resistant human 293T and Jurkat T cell lines expressing Staufen1-TAP (or St-TAP) and TAP control cell lines (Figures 1A-D; Puig et al., 2001). Cells were transfected with pcDNA3 in which a TAP tag was cloned at the carboxy-terminus of the Staufen $1^{55 \mathrm{kDa}}$ cDNA (Villace et al., 2004; Ajamian et al., 2008). Previous studies have demonstrated that St-TAP protein has the same properties as the native protein (Villace et al., 2004). Two of the 12 singlecell clones that were expanded in expressed the fusion protein as assessed by western blotting. St-TAP\#11 was used for all subsequent experiments (Figure 1B; shown in Ajamian et al., 2008), because the expression levels were similar to that of endogenous Staufen $1^{55 \mathrm{kDa}}$. Jurkat St-TAP\#13 (Figure 1C) was used for subsequent purification and characterization of Staufen 1 complexes. A control cell line was also generated expressing only the TAP tag (Figure 1D). The subcellular distribution of TAP and St-TAP proteins in these stable $293 \mathrm{~T}$ cell lines were assessed by IF using a monoclonal anti-Protein A antibody that recognizes the IgG binding domain of Protein A (the carboxy-terminal part of the TAP tag). TAP tag was found to be uniformly distributed throughout the cell (Figure 1E, left panel) and St-TAP was found principally in the cytoplasm of stable expressing cells (Figure 1E, right panel), corresponding to the localization pattern of endogenous Staufen 1 (Wickham et al., 1999; Thomas et al., 2005). These results indicate

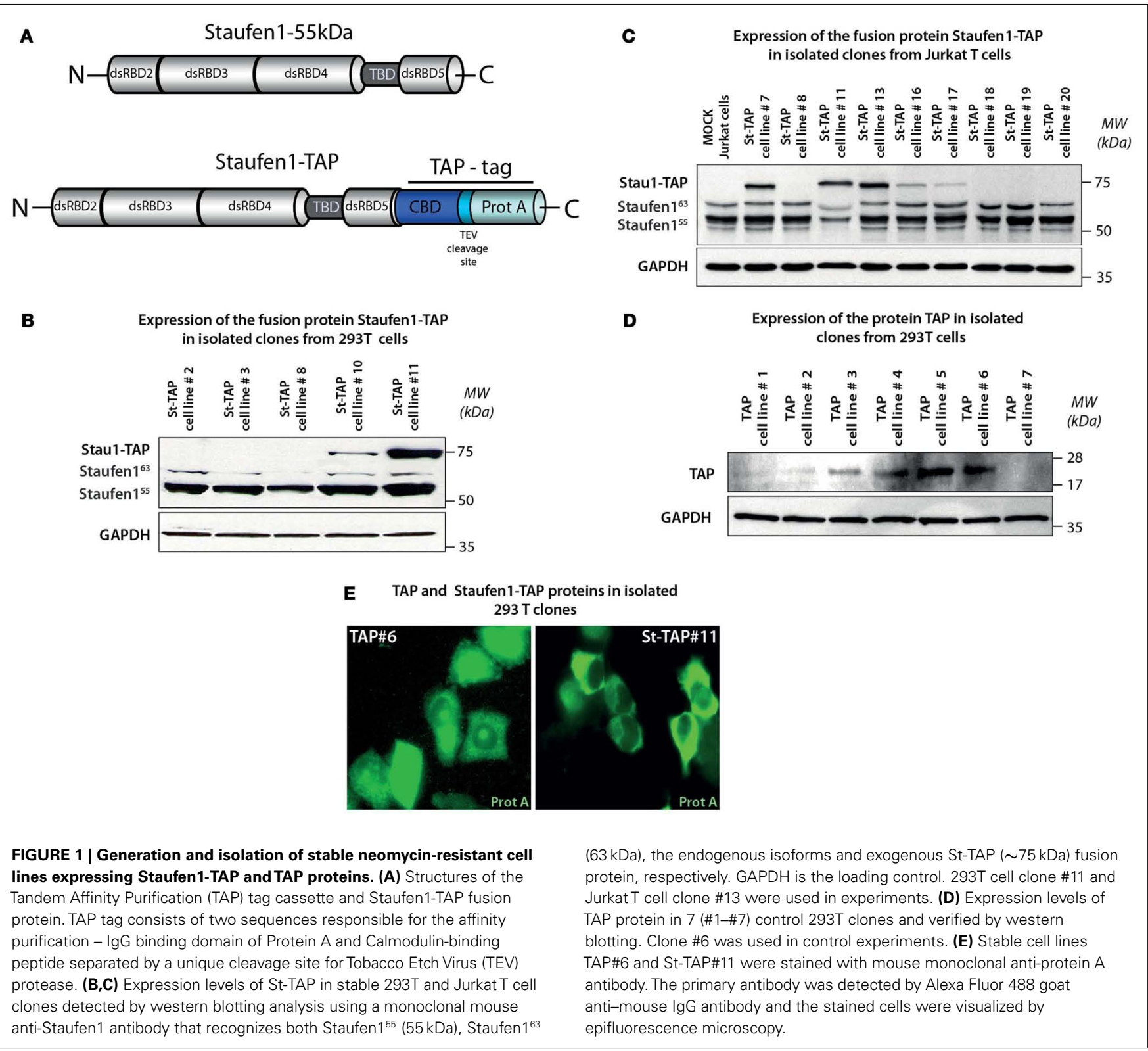


that the Staufen 1 component of the fusion protein, rather than the TAP tag, is responsible for correctly localizing the fusion protein to the cytosol.

PURIFICATION OF STAUFEN1 HIV-1 RIBONUCLEOPROTEIN COMPLEXES We used the TAP-to-MS protocol to discover compositional changes in Staufen1-containing complexes when HIV-1 is expressed. We performed parallel purifications of extracts obtained from stably expressing St-TAP (Mock) or TAP (control) cell lines transiently transfected with pNL4-3. At $40 \mathrm{~h}$ posttransfection cells were harvested and $20 \mathrm{mg}$ total protein was used for TAP purification. We also isolated Staufen 1 complexes from both HIV-1 infected or uninfected Jurkat T cells that expressed St-TAP. Staufen $1^{55 \mathrm{kDa}}$ and St-TAP were present in RNPs both before and after affinity purification (Figures 2A,C). The TEV protease-mediated cleavage of St-TAP $(75 \mathrm{kDa})$ fusion proteins resulted in the formation of St-CBP protein that migrated at $\sim 64 \mathrm{kDa}$ (Figures 2A,C). Both endogenous 55 and $63 \mathrm{kDa}$ isoforms of Staufen1 were recruited to RNPs likely due to their ability to form homo- and heterodimers and to accumulate in RNPs (Martel et al., 2010). When HIV-1 was expressed, higher amounts of endogenous Staufen1 were found in the eluates.
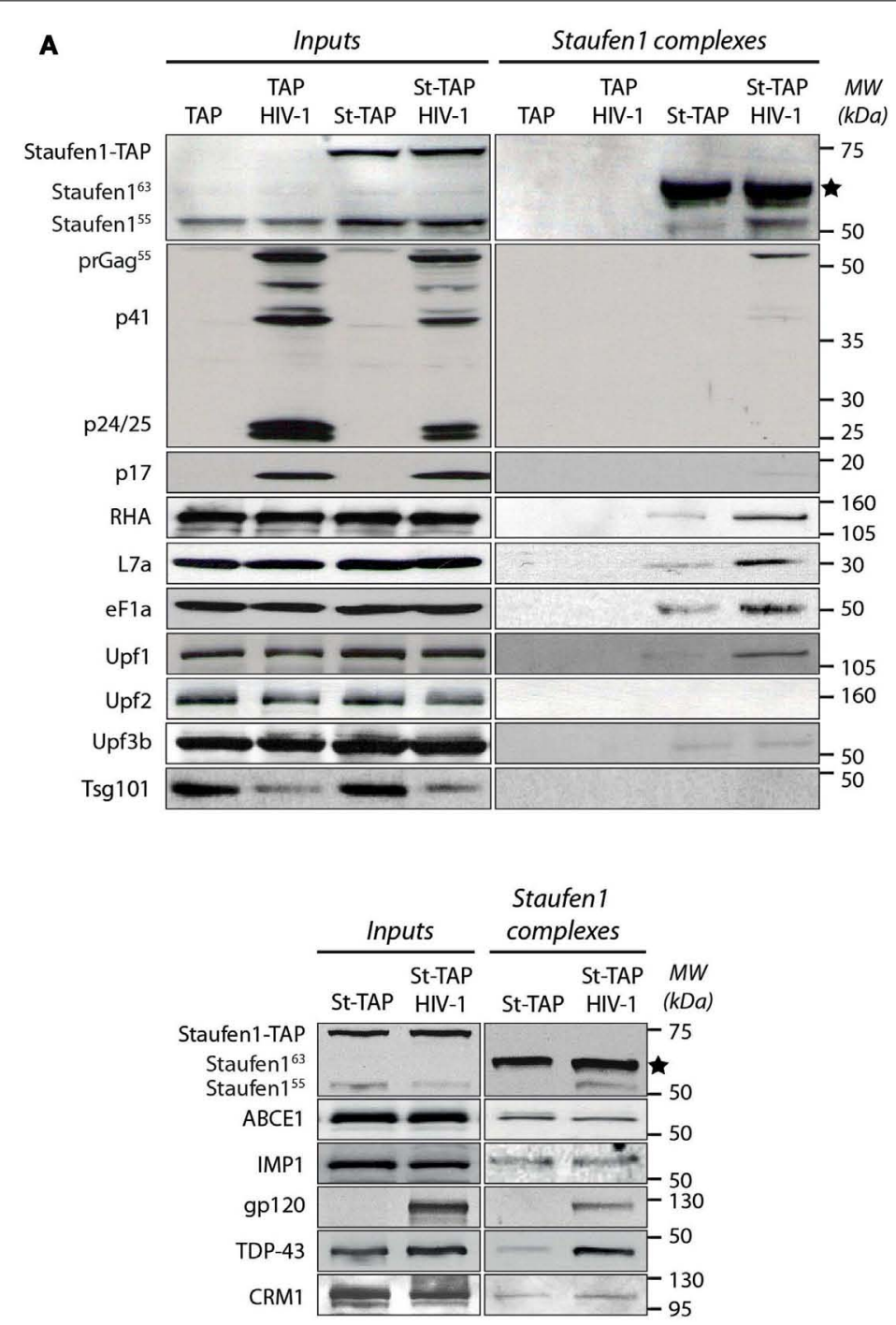

FIGURE 2 | Characterization of the tandem affinity-isolated Staufen $1^{55} \mathrm{kD}$ RNPs by western blot and mass spectrometry analysis. (A) Separation of proteins from cell lysates (Inputs) before (left panels) and after (right panels) tandem affinity purification (Staufen 1 complexes) $0.25 \mathrm{mg}$ of total protein obtained from extracts of TAP (control) or Staufen1-TAP expressing cell lines in the absence or presence of HIV-1 were used for affinity purification. Initially, the membrane was blotted with mouse anti-Staufen 1 monoclonal antibody shown on the top left and right panels. The star $\left(^{*}\right)$ indicates the position of the purified St-CBP protein. (B) The proteins from the eluted
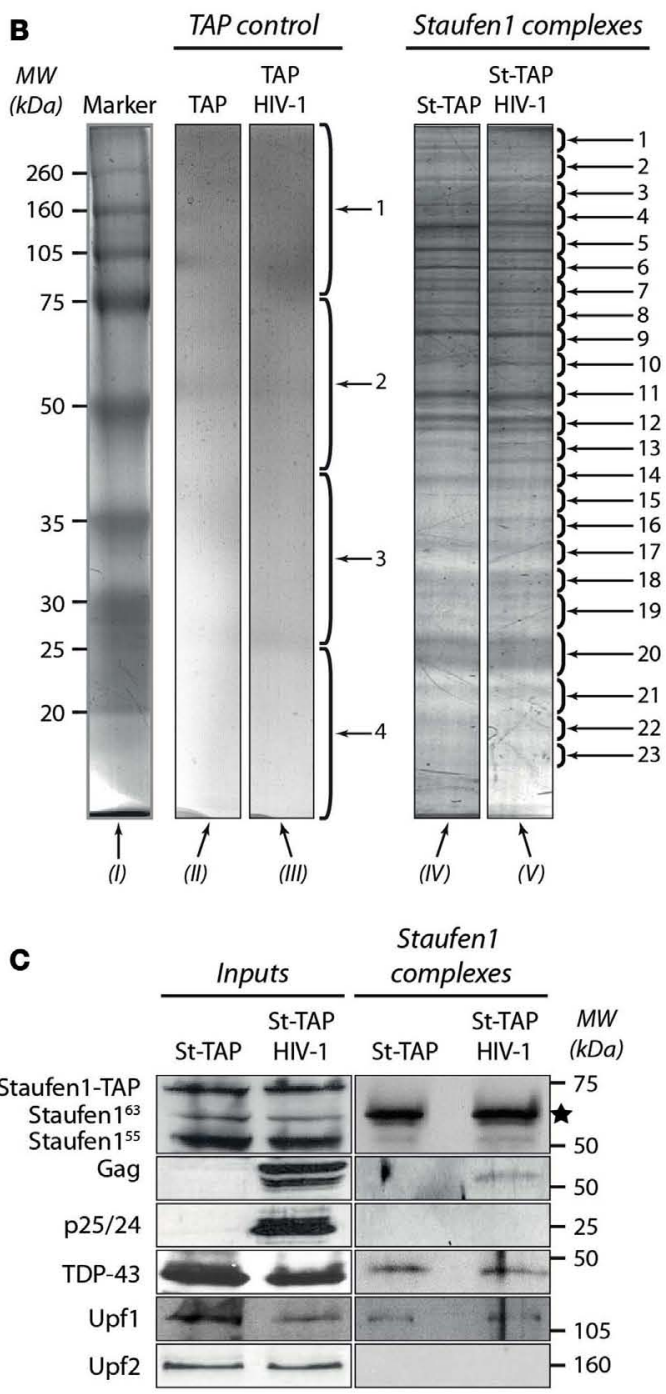

Staufen $1^{55 \mathrm{kDa}}$ complexes and those from TAP alone (control) were purified from $75 \mathrm{mg}$ of total protein, separated on SDS-PAGE and subsequently stained with Bio-Safe Coomassie Blue. Four bands were excised from gel lanes (II) and (III) for the identification of potential contaminating proteins. 23 bands from St-TAP and St-TAP HIV-1 (lanes $I V$ and $V$ ) were excised and analyzed with mass spectrometry. Lane / represents the molecular weights in $\mathrm{kDa}$ of the protein standards. (C) Dual affinity purification of Staufen1 complexes derived from Jurkat T St-TAP stable cell lines in the absence or in the presence of HIV-1. 
Furthermore, the precursor Gag protein was found in association with Staufen 1 but not any of its smaller, mature cleavage products [CA (p24), MA (p17), NC (p7), or p6 (Figures 2A,C)]. This result is in accordance with our previous data showing the selective manner in which Staufen1 and Gag interact (Chatel-Chaix et al., 2004). Interestingly, in the majority of the experiments we also detected $\mathrm{pr} 160^{\mathrm{Gag} / \mathrm{Pol}}(\mathrm{Gag} / \mathrm{Pol})$, probably as a result of its interaction with Staufen1, Gag and the presence of vRNA that facilitates such associations during HIV-1 assembly (Khorchid et al., 2002). The affinity purification was validated by western blotting using antibodies against several proteins that were previously found to associate with Staufen 1 such as RHA, ribosomal protein L7a (Villace et al., 2004) and poly-A binding protein (PABP; Figure 2A; Miroslav P. Milev and Andrew J. Mouland, data not shown). Western blotting analysis revealed that eukaryotic translation elongation factor- $1 \alpha(\mathrm{eF} 1 \alpha)$ is a Staufen1-interacting partner. This is the first time that the association with eF1 $\alpha$ with Staufen 1 has been reported; it nevertheless interacts with Gag and is incorporated in HIV-1 particles (Cimarelli and Luban, 1999).

Previously, Staufen1 was found to interact with the nucleocytoplasmic shuttling protein, Barentsz (Macchi et al., 2003), a component of exon junction complexes and an important player in nonsense-mediated mRNA decay (NMD) - a surveillance process that degrades aberrant $m R N A s$ containing premature termination codons (Palacios et al., 2004). Staufen1-mediated mRNA decay was also described to involve Staufen 1 and the major NMD factor, Upf1 (Kim et al., 2005). Moreover, these two proteins are found in association with APOBEC3G RNPs that might be involved in retroviral restriction (Kozak et al., 2006). These findings provide molecular and biochemical links between mRNA splicing, trafficking and decay. Therefore we wanted to determine the potential association of some of the main NMD factors such as Upf1, Upf2, and Upf3 in Staufen1-containing RNPs in the absence or presence of HIV-1 infection. Our results clearly demonstrate the association of Upf1 with the Staufen1 HIV-1 RNP complexes. When HIV-1 was expressed, we consistently observed approximately threefold more Upf1 eluting from the Staufen 1 column compared to that found when HIV-1 was not expressed (Figures 2A,C). Upf2 was not detected in any of the experiments using $293 \mathrm{~T}$ or Jurkat $\mathrm{T}$ Staufen1-TAP cell lines (Figures 2A,C) indicating that Upf2 is absent or is not stably bound in the Staufen1 RNP (Ajamian et al., 2008). The absence of Upf2 was expected since Staufen 1 and Upf2 compete for binding with Upf1. Upf3b was also detected in St-TAP complexes derived from $293 \mathrm{~T}$ cells as assessed by western blotting (Figure 2A).

We have demonstrated an important role for Staufen 1 in the process of Gag multimerization, trafficking and viral assembly that could be coordinated with a role in the encapsidation of vRNA (Chatel-Chaix et al., 2007; Abrahamyan et al., 2010; Milev et al., 2010). We wished to verify whether the function of Staufen 1 in Gag multimerization, assembly and vRNA encapsidation are linked to the function of other cellular Gag-interacting factors. To this end, we chose the host ATP-binding cassette protein ABCE1 which associates with Gag shortly after its synthesis (Dooher et al., 2007) and is critical for the proper generation of an immature HIV-1 capsid (Zimmerman et al., 2002). As in seen with Staufen1, the
NC domain of Gag is a necessary and sufficient determinant for binding ABCE1 (Zimmerman et al., 2002; Lingappa et al., 2006). Equal amounts of ABCE1 were detected in Staufen1 RNPs isolated from cells with or without HIV-1 expression (Figure 2A, bottom panel). Several studies have demonstrated that tumor susceptibility gene 101 (TSG101) protein binds the N-terminal p6 region of Gag and is responsible for the release of the virus from the plasma membrane (Sun et al., 1999; Babst et al., 2000; Garrus et al., 2001; VerPlank et al., 2001). We did not find TSG101 in the Staufen 1 eluates in any of the cell lines nor could we detect it by mass spectrometry. In fact, other candidate endosomal sorting complex required for transport (ESCRT) proteins were not detected in these Staufen1 RNPs (Miroslav P. Milev and Andrew J. Mouland, data not shown). Thus, despite its interaction with the viral protein Gag, TSG101 appears to be excluded from these particular Staufen1 RNPs suggesting separable functions during HIV-1 replication. Likewise, we did not detect either Vif or Vpr by mass spectrometry and/or western blotting analyses, both welldescribed interacting partners of Gag (Lavallee et al., 1994; Kondo et al., 1995; Bouyac et al., 1997; Syed and McCrae, 2009). We propose that this negative result could be due to their low abundance in Staufen1 HIV-1 complexes or that these viral proteins interact with distinct subpopulations of Gag that exclude Staufen1 (Klein et al., 2007).

\section{IDENTIFICATION OF PROTEINS ASSOCIATED WITH STAUFEN1 HIV-1 RNPs}

After validating our RNP purification protocol by western blotting, we proceeded to mass spectrometry analysis to identify proteins that associate with Staufen 1 in these particles both in the absence or presence of HIV-1. For these experiments, stably expressing TAP cells were mock transfected or transfected with a proviral plasmid expressing HIV-1 (pNL4-3), lysed and then used for affinity purification. In the eluates from the control TAP samples [Figure 2B, lines $(I I)$ and $(I I I)$ ] we detected a few discrete bands. We sectioned the TAP gel lanes into four pieces (shown with numbers) and analyzed them by mass spectrometry. The proteins that were detected included keratins, immunoglobulins, interferon alpha inducible protein (IFI6), tubulin beta- 2 and heat shock protein 90 and since they were found in the control TAP samples, they were considered to be contaminants.

Stable St-TAP cell lines were then mock transfected or transfected with pNL4-3. Lysates were harvested and following SDSPAGE and Coomassie Blue staining, we observed a similarity in banding pattern between Staufen1-TAP and Staufen1-TAP HIV-1 RNPs [Figure 2B, lines $(I V)$ and $(V)$ ]. In a typical experiment, we excised at least 23 bands from the St-TAP lane and corresponding bands from St-TAP HIV-1 lane. Each band was subjected to LC-MS/MS analysis and the data was concatenated and searched against either the NCBI nr human or virus databases as described in Materials and Methods. A separate randomized decoy database search was performed and the search results were filtered to achieve a False Discovery Rate (FDR) of less than 1\%. This corresponded to a score cutoff of 48 and 47 for the human and viral databases, respectively.

We typically detected about 200 proteins in both Staufen 1-TAP control and Staufen1-TAP HIV-1 RNPs (Figure 3; Tables S1 and 


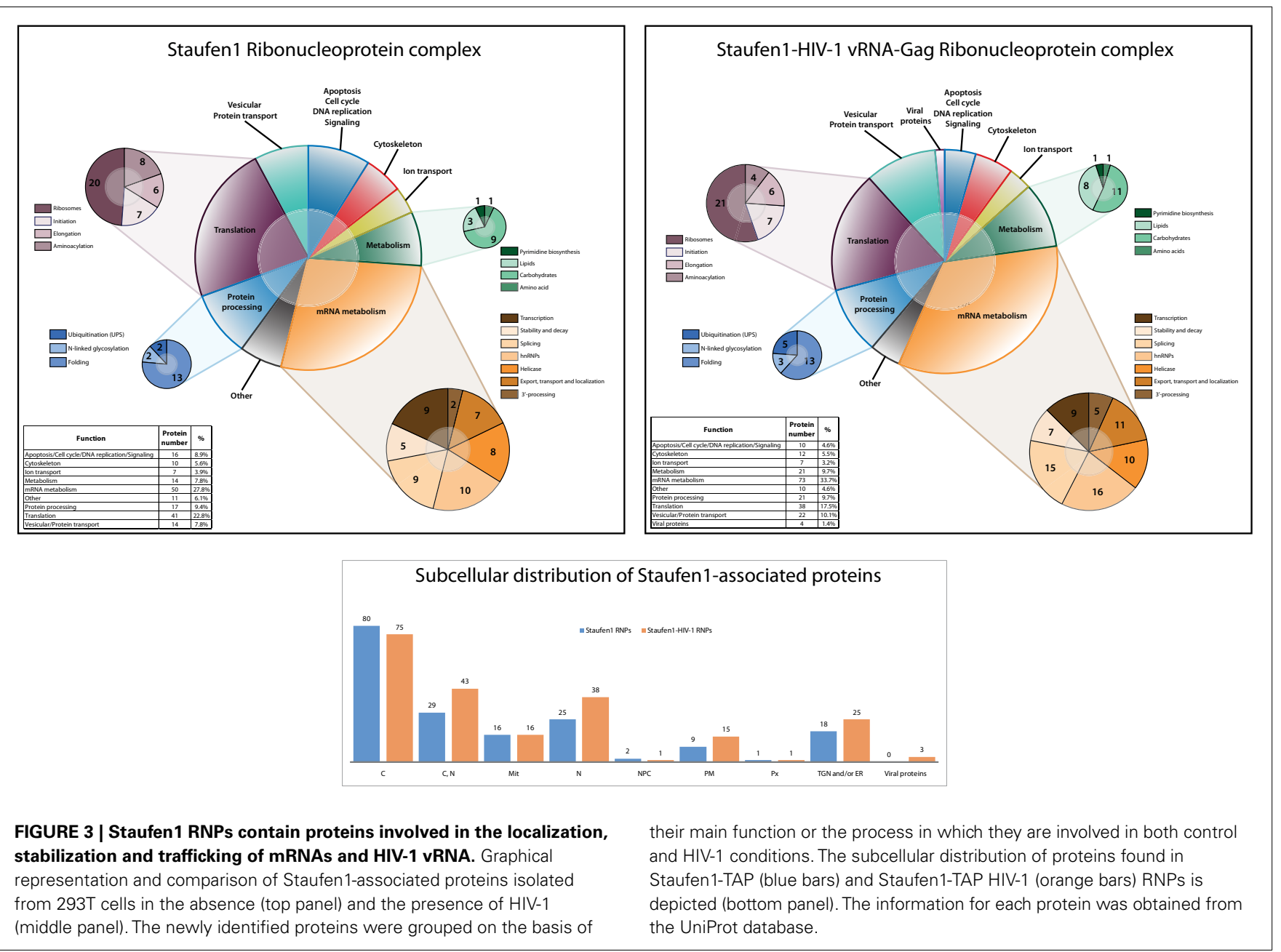

S2 in Supplementary Material). As expected, some of the proteins identified had been previously shown to interact and/or associate with Staufen1, such as hnRNP U, RHA, NFAR, nucleolin, $\alpha$-tubulin and numerous ribosome subunits (Brendel et al., 2004; Villace et al., 2004). The regulator of nonsense transcripts, Upf1, was also identified (Kim et al., 2005). The majority of the proteins were detected with two or more unique peptides; single peptide hits are also reported in the appended Tables S1 and S2 in Supplementary Material.

We divided all identified proteins from both cohorts into several main categories in respect to their known functions. As shown in the Figure 3, we generated 10 functional categories, including viral proteins in the case when HIV-1 was expressed. The largest group encompassed mRNA-binding proteins that participate in different aspects of mRNA metabolism in the cell (RNA transcription, splicing, stability, transport and degradation) and represent $\sim 29 \%$ of the total number of proteins in the Staufen 1 RNPs and $\sim 35 \%$ of the total number of proteins in Staufen1HIV-1 RNPs. These proteins included numerous heterogeneous nuclear ribonucleoproteins (RNP), DEAD-box family helicases and NMD factors Upf1 and Upf3b [detected by western blot in both types RNPs (Figure 2A) and by mass spectrometry - only in Staufen1 HIV-1 RNPs (Table 1)]. Splicing and mRNA transport factors, such as SFPQ, SF3B2 and endogenous Staufen1 and nucleocytoplasmic shuttling proteins, such as nucleolin, nuclear factor associated with dsRNA, NFAR-1 $90 \mathrm{kDa}$ isoform and YB-1 (a universal component of cytoplasmic mRNPs) were also included with this group. Several new mRNA-binding components associated within Staufen 1 in both control and HIV-1 conditions. These included leucine-rich protein $130 \mathrm{kDa}$, LRP130, an RNA-binding protein that accumulates with $\mathrm{mRNPs}$ at the nuclear envelope and endoplasmic reticulum (Tsuchiya et al., 2004). Three members of the highly conserved VICKZ family of RNA-binding proteins (Vg1 RBP/Vera, IMP1,2,3, CRD-BP, KOC, ZBP-1) and insulinlike growth factor II mRNA-binding protein 1, 2 and 3 (IMP1 and IMP2 in the native complexes and IMP1 and IMP3 in those purified from HIV-1-expressing cells) were also detected [Reviewed in (Yisraeli, 2005)]. The RNA/DNA-binding protein TDP-43 was detected by mass spectrometry only in HIV-1-containing complexes, but was later confirmed by western blotting analysis in both the presence and absence of HIV-1. Structurally analogous to the hnRNPs, this protein was originally described as a factor that modulates HIV-1 gene expression at the transcriptional level (Ou et al., 1995). 
Table 1 | Unique proteins identified by mass spectrometry in Staufen1-HIV-1 RNPs.

\begin{tabular}{|c|c|c|c|}
\hline Protein name* & $\begin{array}{l}\text { UniProt accession } \\
\text { number** }\end{array}$ & $\begin{array}{l}\text { Role in HIV-1 } \\
\text { replication? }\end{array}$ & Reference \\
\hline 26S protease regulatory subunit S10B (PSMC6) & P62333 & Unknown & N/A \\
\hline 60S ribosomal protein L29 (RPL29) & P47914 & Unknown & N/A \\
\hline 7-dehydrocholesterol reductase (DHCR7) & Q9UBM7 & Yes & (van't Wout et al., 2005) \\
\hline Actin-related protein $2 / 3$ complex subunit 4 & P59998 & Yes & (Komano et al., 2004; Chertova et al., 2006) \\
\hline ADP-ribosylation factor 6 (ARF6) & P62330 & Yes & (Ono et al., 2004) \\
\hline Alpha-internexin (INA) & Q16352 & Unknown & $\mathrm{N} / \mathrm{A}$ \\
\hline AP-2 complex subunit mu (AP-2M1) & Q96CW1 & Yes & $\begin{array}{l}\text { (Le Gall, 1998; Craig et al., 2000; Batonick } \\
\text { et al., 2005) }\end{array}$ \\
\hline AP-3 complex subunit delta-1 (AP-3D1) & 014617 & Yes & (Dong et al., 2005) \\
\hline CDP-diacylglycerol-inositol 3-phosphatidyltransferase (CDIPT) & 014735 & Unknown & N/A \\
\hline Copine-3 & 075131 & Unknown & (Chertova et al., 2006) \\
\hline Delta-1-pyrroline-5-carboxylate synthetase (ALDH18A1) & P54886 & Unknown & $\mathrm{N} / \mathrm{A}$ \\
\hline Double-stranded RNA-specific adenosine deaminase (ADAR) & P55265 & Yes & (Phuphuakrat et al., 2008; Doria et al., 2009) \\
\hline Dynamin-2 (DNM2) & P50570 & Yes & (Pizzato et al., 2007) \\
\hline E3 ubiquitin-protein ligase (BRE1A) & Q5VTR2 & Unknown & $N / A$ \\
\hline Env & P03377 & Yes & (Freed, 2001) \\
\hline Eukaryotic initiation factor 4A-III (elF4A3) & P38919 & Unknown & $\mathrm{N} / \mathrm{A}$ \\
\hline Eukaryotic translation initiation factor 3 subunit E (elF3E) & P60228 & Unknown & N/A \\
\hline Gag & P12493 & Yes & (Freed, 1998) \\
\hline Gag/Pol & P12493 & Yes & (Jacks et al., 1988) \\
\hline GTP-binding nuclear protein Ran & P62826 & Yes & (Askjaer et al., 1998) \\
\hline HIV-1 Rev-binding protein 2 & Q13601 & Unknown & N/A \\
\hline Importin-7 & 095373 & Yes & (Fassati et al., 2003; Zaitseva et al., 2009) \\
\hline Insulin-like growth factor II mRNA-binding protein-3 & 000425 & Unknown & N/A \\
\hline IQ motif containing GTPase activating protein 1 & P46940 & Unknown & (Chertova et al., 2006) \\
\hline Leucine-rich repeat-containing protein 59 (LRRC59) & Q96AG4 & Unknown & $N / A$ \\
\hline Long-chain-fatty-acid-CoA ligase 3 (ACSL3) & 095573 & Unknown & $N / A$ \\
\hline Mannosyl-oligosaccharide glucosidase (MOGS) & Q13724 & Unknown & $N / A$ \\
\hline Nef & P05855 & Yes & (Arhel and Kirchhoff, 2009) \\
\hline NF-kappaB repressing factor (NRF) & A3F768 & Yes & (Dreikhausen et al., 2005) \\
\hline Non-POU domain-containing octamer-binding protein (NONO) & Q15233 & Yes & (Zolotukhin et al., 2003) \\
\hline Nuclear pore complex protein 155 (Nup155) & 075694 & Yes & (Brass et al., 2008; Lee et al., 2010) \\
\hline Peroxiredoxin-6 & P30041 & Unknown & (Chertova et al., 2006) \\
\hline Phosphatidylserine synthase 1 (PTDSS1) & P48651 & Unknown & N/A \\
\hline Pre-mRNA 3'-end-processing factor FIP1 (FIP1L1) & Q6UN15 & Unknown & N/A \\
\hline
\end{tabular}


Table 1 | Continued

\begin{tabular}{|c|c|c|c|}
\hline Protein name* & $\begin{array}{l}\text { UniProt accession } \\
\text { number** }\end{array}$ & $\begin{array}{l}\text { Role in HIV-1 } \\
\text { replication? }\end{array}$ & Reference \\
\hline Probable ATP-dependent RNA helicase (DDX17) & Q92841 & Unknown & $\mathrm{N} / \mathrm{A}^{* * *}$ \\
\hline Probable ATP-dependent RNA helicase (DDX27) & Q96GQ7 & Unknown & N/A \\
\hline Programmed cell death 8 (AIFM1) & 095831 & Unknown & N/A \\
\hline Protein transport protein Sec61 subunit alpha isoform 1 (SEC61A1) & P61619 & Unknown & N/A \\
\hline Protein tyrosine phosphatase-like protein (PTPLAD1) & Q9P035 & Unknown & N/A \\
\hline Putative RNA-binding protein Luc7-like 2 & Q9Y383 & Unknown & N/A \\
\hline Pyruvate dehydrogenase E1 component subunit beta (PDHB) & P11177 & Unknown & (Ringrose et al., 2008) \\
\hline Ras-related GTP-binding protein A (RRAGA) & Q7L523 & Unknown & N/A \\
\hline Ras-related protein Rab-10 & P61026 & Unknown & (Chertova et al., 2006) \\
\hline Ras-related protein Rab-5C & P51148 & Yes & $\begin{array}{l}\text { Nidricaire and Tremblay, 2005; Chertova } \\
\text { et al., 2006) }\end{array}$ \\
\hline Ras-related protein Rab-8A & P61006 & Unknown & (Chertova et al., 2006) \\
\hline Ribonucleoprotein PTB-binding 1 & Q8IY67 & Unknown & N/A \\
\hline Signal recognition particle receptor subunit beta (SRPRB) & Q9Y5M8 & Unknown & N/A \\
\hline Spliceosome RNA helicase (BAT1) & Q13838 & Unknown & (Limou et al., 2009) \\
\hline Splicing factor, arginine/serine-rich 13A (SFRS13A) & 075494 & Unknown & N/A \\
\hline Splicing factor, arginine/serine-rich 4 (SFRS4) & Q08170 & Unknown & N/A \\
\hline Splicing factor, proline- and glutamine-rich (SFPQ) & P23246 & Yes & (Zolotukhin et al., 2003) \\
\hline T-complex protein 1 subunit beta & P78371 & Unknown & N/A \\
\hline THO complex 4 (THOC4) & Q86V81 & Unknown & N/A \\
\hline THO complex subunit 2 (THOC2) & Q8NI27 & Unknown & N/A \\
\hline T-plastin polypeptide (plastin-3) & P13797 & Unknown & N/A \\
\hline Tubulin alpha-4A chain & P68366 & Unknown & (Chertova et al., 2006) \\
\hline V-type proton ATPase subunit d 1 & P61421 & Unknown & (Chertova et al., 2006) \\
\hline Zinc finger RNA-binding protein (ZFR) & Q96KR1 & Unknown & N/A \\
\hline
\end{tabular}

*Viral proteins are highlighted; **Universal Protein Resource - UniProt database [http://www.uniprot.org/]; *** Not applicable.

The second most predominant category relates to proteins involved in RNA translation ( $\sim 23$ and $\sim 18 \%$ in the absence and presence of HIV-1, respectively) and includes ribosomal, translation initiation and elongation factors and several aminoacyl-tRNA synthetases. Proteins such as PABP1, eukaryotic translation initiation, and elongation factors - eIF3 $(\alpha, \beta$ and $\varepsilon$ ), eIF4A (two isoforms -1 and 3 ) and eF1 ( $\alpha, \gamma$ and $\delta$ isoforms) were also detected.

Proteins involved in cell metabolism represented $\sim 8 \%$ of the total number of proteins in Staufen1-containing RNPs isolated in the absence of HIV-1 and $\sim 9 \%$ in the presence of HIV-1. These included enzymes that regulate different aspects of the general cellular metabolism of carbohydrates, lipids, amino acids, and nucleotides, such as pyruvate kinase and pyruvate dehydrogenase, lactate dehydrogenase and glyceraldehyde-3-phosphate dehydrogenase, fatty acid synthase, ATP-citrate synthase and others (Figure 3; Tables S1 and S2 in Supplementary Material).

Diverse proteins involved in cytoskeleton formation and structure ( $\sim 4$ and $\sim 5 \%$ in the absence HIV-1 and presence of HIV-1, respectively), including actin, tubulin, vimentin, as well as IQGAP1 were detected (Figure 3; Tables S1 and S2 in Supplementary Material). We also placed Matrin 3 in this category as it is a novel Staufen1-binding partner that was originally reported to be one of the major structural proteins of the inner nuclear matrix (Belgrader et al., 1991). An interesting feature of this protein is its ability to retain A-I edited dsRNAs in the nucleus (Reviewed in DeCerbo and Carmichael, 2005). Moreover, it has been shown in association with APOBEC3G RNPs (Kozak et al., 2006) and with $3^{\prime}$-untranslated region (UTR) of the hepatitis C genome (Harris et al., 2006).

Approximately 8\% (-HIV-1) and 10\% (+HIV-1) of Staufen1binding partners were vesicular and protein transport proteins. As mentioned earlier, TSG101, a member of ESCRT-I was not detected by western blotting or by mass spectrometry. Instead, we identified some other proteins involved in the control of endosomal dynamics and in intra-Golgi vesicular transport, including vesicle budding from Golgi membranes. These included Rasrelated proteins (Rab-5C, Rab8, Rab-10), some of the coatomer protein complex subunits - COP $(\alpha, \gamma$ and $\zeta)$, adaptor proteins (AP-2, AP-3) and ADP-ribosylation factors (1, 4, 5 and 6). In addition, some cellular factors regulating the processes of protein folding (heat shock proteins, T-complex proteins, Calnexin), ubiquitination and $\mathrm{N}$-linked glycosylation (Ribophorin-1) constitute the protein processing group [ $\sim 8 \%(-\mathrm{HIV})$ and $\sim 9 \%(+\mathrm{HIV}-1)]$.

Finally, the remaining identified proteins included those involved in ion transport (including sodium/potassiumtransporting ATPase, several ATP synthases) and apoptosis/cell cycle/DNA replication/signaling (CDC5L, MCM7 and RACK1), while the remaining proteins were grouped under "others" and 
included mitochondrial and nucleocytoplasmic transport proteins (Nup155, Importin 1, Importin-7, Xpo1, Xpo2 and ADP/ATP translocase; Figure 3 and see Tables S1 and S2 in Supplementary Material).

We detected 45 proteins from Staufen 1 HIV-1 RNPs (including viral proteins such as Gag, Gag/Pol, Env and Nef; Tables S1 and S2 in Supplementary Material) that are virion-associated (Ott, 2002, 2008; Cantin et al., 2005; Komano et al., 2005; Chertova et al., 2006; Goff, 2007) representing $22 \%$ of the total number of proteins found in the Staufen 1 HIV-1 complexes. Among them were RHA, IQGAP1, actin, vimentin, eF1 $\alpha$, Staufen1, IMP1 and heat shock proteins Hsp60, Hsp70 and Hsc70. The latter three are incorporated within the membrane of the viruses and are important for virus infectivity (Gurer et al., 2002). Upf1, which is found in the HIV-1 RNP, also represents a virion-incorporated protein (Abrahamyan et al., 2010).

\section{CHARACTERIZATION OF INTERACTIONS BETWEEN STAUFEN1 AND SEVERAL NOVEL PARTNERS USING BIOCHEMICAL AND IMMUNOFLUORESCENCE METHODS}

We confirmed the association of several proteins with Staufen 1 complexes using IP and IF analyses. For the purpose of these experiments, we chose three predominantly nuclear proteins: AU-rich element RNA binding protein 1, AUF1, TAR DNA-binding protein, TDP-43 and chromosomal regional maintenance protein 1 (CRM1 or Xpo1), a factor that mediates the nuclear export and ABCE1 (also known an HP68). IP experiments were performed with lysates derived from HeLa cells. To determine the RNA dependence of these interactions, equal amounts of lysates were treated with or without RnaseA for $30 \mathrm{~min}$ on ice before IP. Our results demonstrate the RNA-independent character of Staufen 1 interactions with CRM1 and ABCE1 (Figures 4A,B, IP panels), whereas those between both Staufen 1 and TDP-43 and Staufen1 and AUF1 appeared to be RNA-dependent (Figures 4C,D, IP panels). We detected IMP1 in three independent MS analyses and further confirmed its presence in affinity-isolated complexes using polyclonal rabbit anti-IMP1 antibody (Figure 2A, bottom panel). IMP1 is a human ortholog of chicken Zipcode binding protein 1 (ZBP-1) and belongs to VICKZ protein family (Yisraeli, 2005). Different studies indicate similar functions for IMP1 and Staufen 1 with respect to mRNA transport, translational control and localization. IMP1 binds fragile $\times$ mental retardation protein (Rackham and Brown, 2004) and PABP1 (Patel and Bag, 2006) and associates with APOBEC3G (Kozak et al., 2006), YB1, nucleolin and hnRNP A1 (Jonson et al., 2007), proteins that also associate with Staufen1. Recently, IMP1 has been found to bind to HIV-1 Gag (Roy et al., 2006) and in our own work this protein also associates with lipid raft domains (Milev et al., 2010). We performed IP experiments for IMP1 (Figure 4E, IP panel) and observed that its association with Staufen 1 was also RNA-independent.

To further demonstrate the interrelationships between Staufen 1 and these proteins, we performed laser scanning confocal microscopy to examine their distribution in cells. We transfected HeLa cells with plasmids expressing Staufen1-HA and $24 \mathrm{~h}$ later, we fixed and stained the cells with antibodies recognizing the HA-epitope and the endogenous proteins that were used in the IPs, with the exception that we used an anti-GFP to detect IMP1-VenusC (IMP1-VC). We observed co-localization of Staufen1 with ABCE1 and partial co-localization with TDP43, AUF1 (Lund et al., 2012) and CRM1 [Figures 4A-D, colocalization with Staufen1 panels; Manders' coefficients (\%) are shown]. As expected, Staufen 1 and IMP1 co-localized in cytoplasmic particles, but this was only true for a proportion of these proteins (Figure 4E, co-localization with Staufen1 panel). Finally, the possible interactions of these novel Staufen1 partners with vRNA and Gag were elucidated by combined FISH and IF co-analyses in HIV-1-expressing cells. We transfected HeLa cells with both pNL4-3 proviral DNA plasmids coding for IMP1VenusC (Figures 4A-E, distribution $+H I V-1$ panels). Cells were fixed and stained with rabbit anti-CRM1, anti-ABCE1 anti-TDP43, anti-AUF1, or anti-GFP (to detect IMP1-VenusC; all in red, Figures 4A-E, distribution + HIV-1 panels), along with sheep antip17 to detect Gag (shown in blue) and FISH was performed to detect viral RNA (shown in green). The presence of HIV-1 caused the partial accumulation of AUF1 in the cytoplasm. The mechanism, however, that underlines this phenomenon is unclear but could be due to the HIV-1 imposed block on nuclear import (Monette et al., 2009) and the functional significance of this interaction was recently demonstrated (Lund et al., 2012). Importantly, ABCE1, currently implicated in the generation of HIV-1 capsids, co-localized with the vRNA. At present, we do not know if this is via a direct or indirect interaction. The co-localization of IMP1 with viral components was estimated in cells simultaneously transfected with IMP1-VenusC and pNL4-3 plasmids. We noticed that cells overexpressing IMP1-VenusC (Figure 4E, shown with white arrows) had an apparent decrease in the signal for vRNA. Cells that did not express or expressed IMP1-VenusC at lower levels showed higher accumulations of vRNA (Figure 4E, white arrow head). This negative effect on vRNA in HIV-1 positive cells was observed in more than $55 \%$ of the cells.

\section{SUCROSE DENSITY GRADIENT ANALYSIS OF STAUFEN1 HIV-1 RNPS}

Sucrose density gradient analyses were then performed to further characterize Staufen1 RNP dynamics when HIV-1 was expressed. The biochemical examination of these RNPs is important since Staufen 1 is found in several RNPs relevant to HIV-1 (Chiu et al., 2006; Abrahamyan et al., 2010) but it also selectively associates with the vRNA in complex with Gag and other host proteins (Chatel-Chaix et al., 2004, 2008; Ajamian et al., 2008). Moreover, in our earlier study, we demonstrated that Staufen1 RNPs were plastic in size but co-associated with Gag and vRNA signals (Abrahamyan et al., 2010). We therefore assessed the distribution of Staufen 1 RNPs by sucrose density centrifugation to determine how HIV-1 influences this. HA-Staufen 1 was transfected into HeLa cells without or with pNL4-3 proviral HIV-1 DNA. Lysates were processed for sucrose density gradient analyses. Fractions were collected from the top of the gradient and HIV-1 vRNA was quantitated by slot blot analysis. An aliquot of each gradient fraction was run on SDS-PAGE and western blotting was performed to identify Staufen1-HA and several of the newly identified members of Staufen1-TAP-containing host proteins (e.g., RP-L7a, TDP-43 and ABCE1, Table S2 in Supplementary Material) and Gag in HIV1 samples (Figures $\mathbf{5 A , B}$ ). In some cases, lysates were treated with 


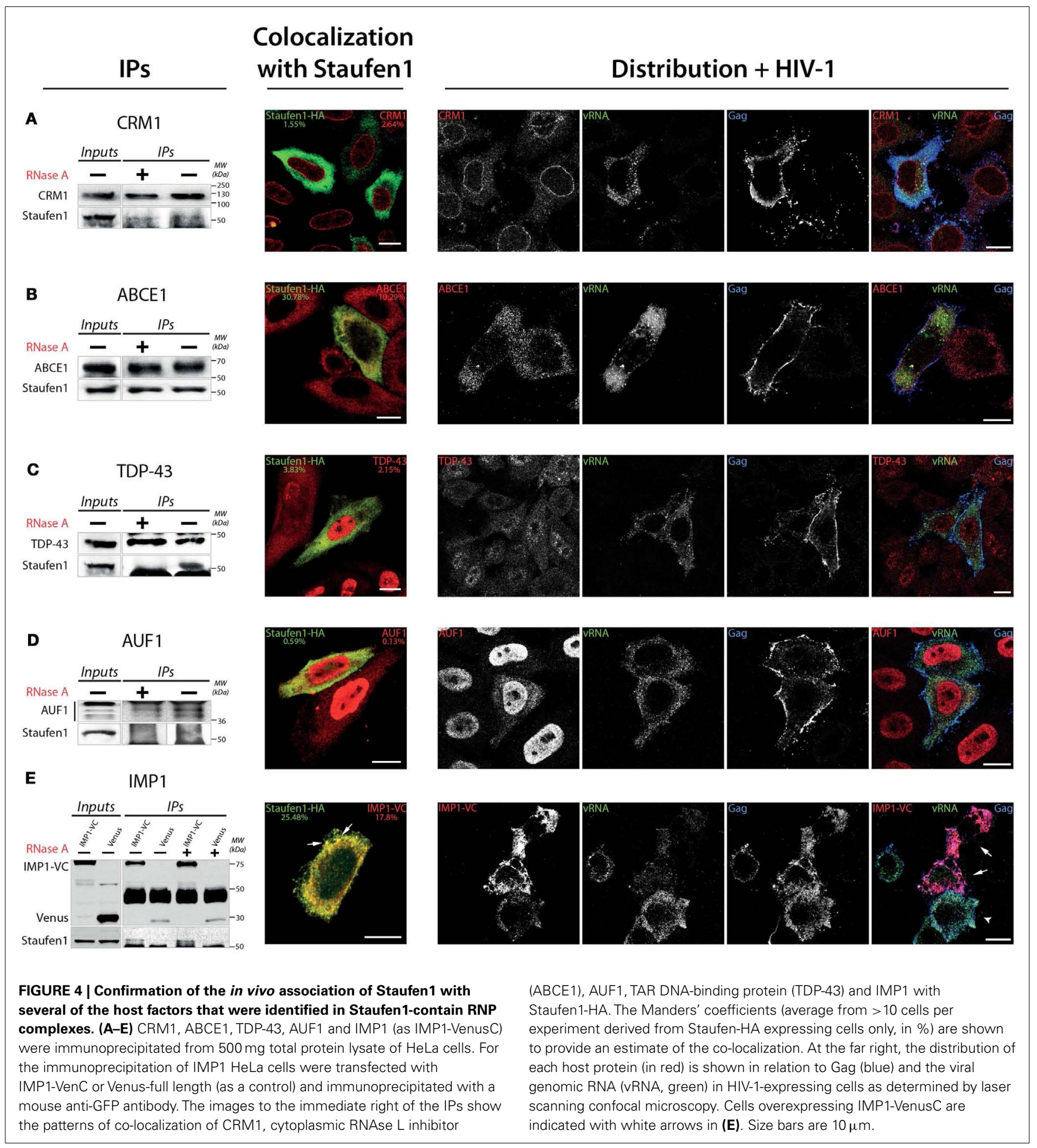

RNAse A to determine RNA-dependency. These analyses revealed that there was no consistent shift in the sedimentation profile of Staufen1-HA complexes in mock and HIV-1-expressing cells and they mainly fractionated in denser fractions \#11-18 (Figure 5A). This was also true for those for the selected Staufen1-associated host proteins. However, Gag sedimented in two regions of the density gradient, in both a light (fractions \#1-7) and a more dense region (fractions \#12-20; Figure 5B), while the vRNA only sedimented in very dense fractions (\#16-20) in this assay. RNAse A treatment eliminated the vRNA, but also disrupted the distribution of viral and host proteins in the dense fractions leading to their migration in lighter density fractions, with the exception of the 


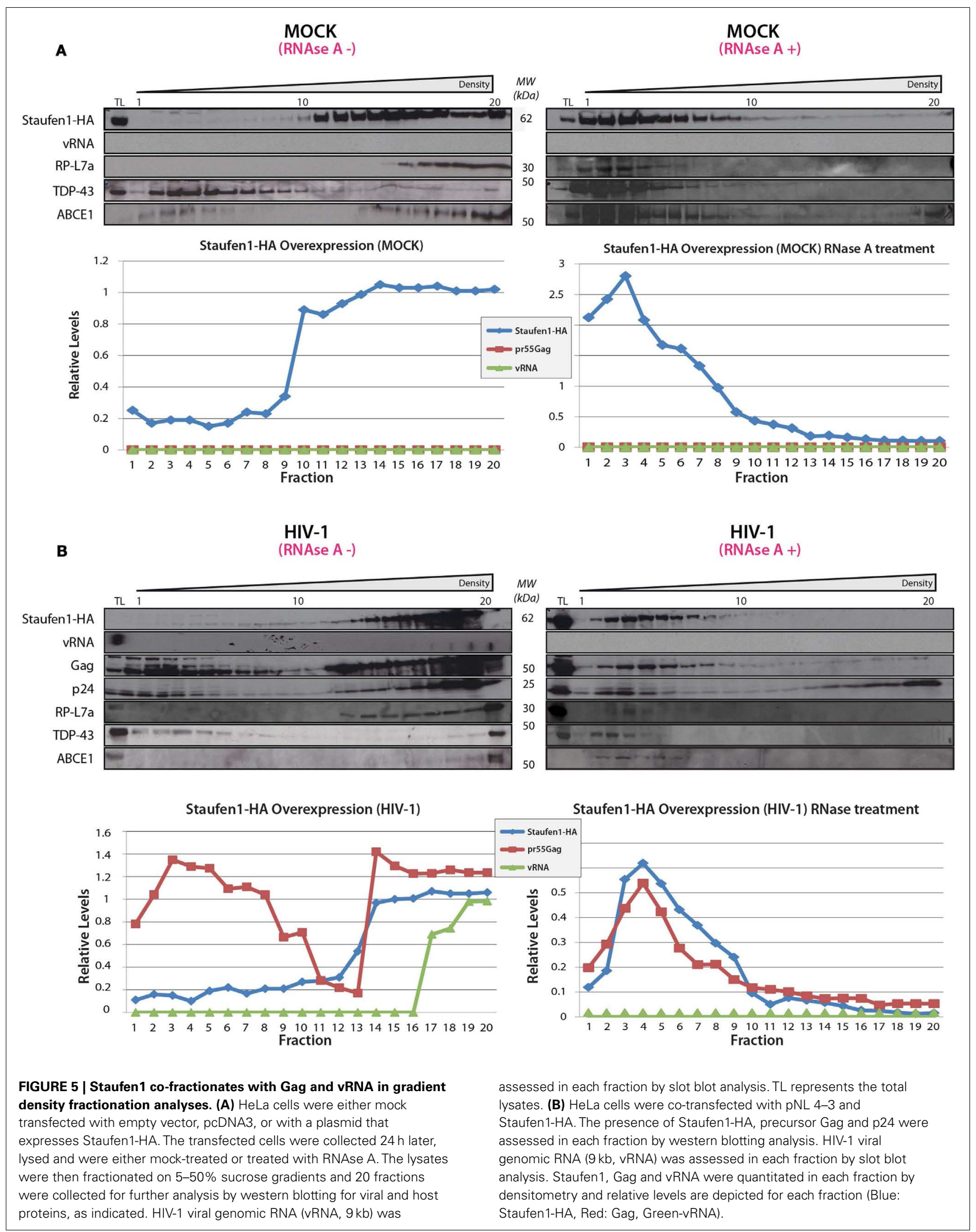


processed form of Gag, p24, which likely represents capsids or virus particles that are membrane-bound (Levesque et al., 2006). The precursor to p24, p25 was also observed in the lighter fractions supporting this notion (Figure 5 and below). We have shown that the Staufen1-Gag interaction is RNA-independent and in close proximity (Chatel-Chaix et al., 2004) so these results indicate that Gag is recruited to pre-existing Staufen 1 RNPs as we demonstrated earlier (Milev et al., 2010) but also, it remains associated to Staufen 1 when viral and cellular RNAs are in limiting supply. This notion is also supported in experiments in which a Gag-less pNL4-3 is expressed. This proviral DNA will express all viral proteins and RNAs except for Gag and Gag/Pol (Poon et al., 2002). When expressed alone (Figure 6A) or when Staufen1-HA is overexpressed (Figure 6B), the sedimentation profiles for vRNA were not appreciably affected in the absence of Gag. This is consistent with our recent findings that showed that Staufen 1 and vRNA co-localized significantly in the absence of Gag under the same experimental conditions (Abrahamyan et al., 2010). When Gag expression was rescued by the expression of a Rev-dependent Gag expressor (Lingappa et al., 2006; Figure 6C), the distribution of vRNA was consistently found to be shifted toward the lighter fractions, that might be specific to this rescue experiment (i.e., due to trans expression of Gag) because the vRNA is found in the penultimate fractions when pNL4-3 is expressed (Figure 5). Further experimentation will be required to characterize the function of these lighter RNPs upon Gag rescue in trans.

In the experiments above, endogenous Staufen 1 is abundantly expressed that could allow the assembly of Staufen1 viral RNPs. In conditions when endogenous Staufen 1 is depleted by siRNA, we have shown that large Staufen1 RNPs (SHRNPs) formed in the vicinity of the nucleus and in the cytoplasm. These structures were proposed to be supraphysiologic RNPs that could serve as scaffolds for viral assembly and vRNA encapsidation. We investigated by density gradient analysis whether the SHRNPs represented a super-dense RNP or amalgamations of many smaller RNPs. HeLa cells were transfected with pNL4-3 DNA and either siNS or siStaufen 1 siRNAs and lysates were prepared for gradient analyses. While siStaufen 1 treatment again resulted in reduced Gag synthesis (Abrahamyan et al., 2010; Figure 7A), the sedimentation profiles for vRNA and Gag did not appreciably change (Figures 7B,C). However, the relative levels of Gag in light and dense gradient fractions were modulated such that a less abundant signal for Gag in the dense fractions was observed. This could be the populations of Gag influenced by Staufen 1 expression levels and functionally relevant for the assembly of dense RNPs or represent a population of Gag with a specific function (Klein et al., 2007). Importantly, these results provide evidence that the larger Staufen1 RNPs observed in Staufen1 depletion conditions likely represent aggregations of

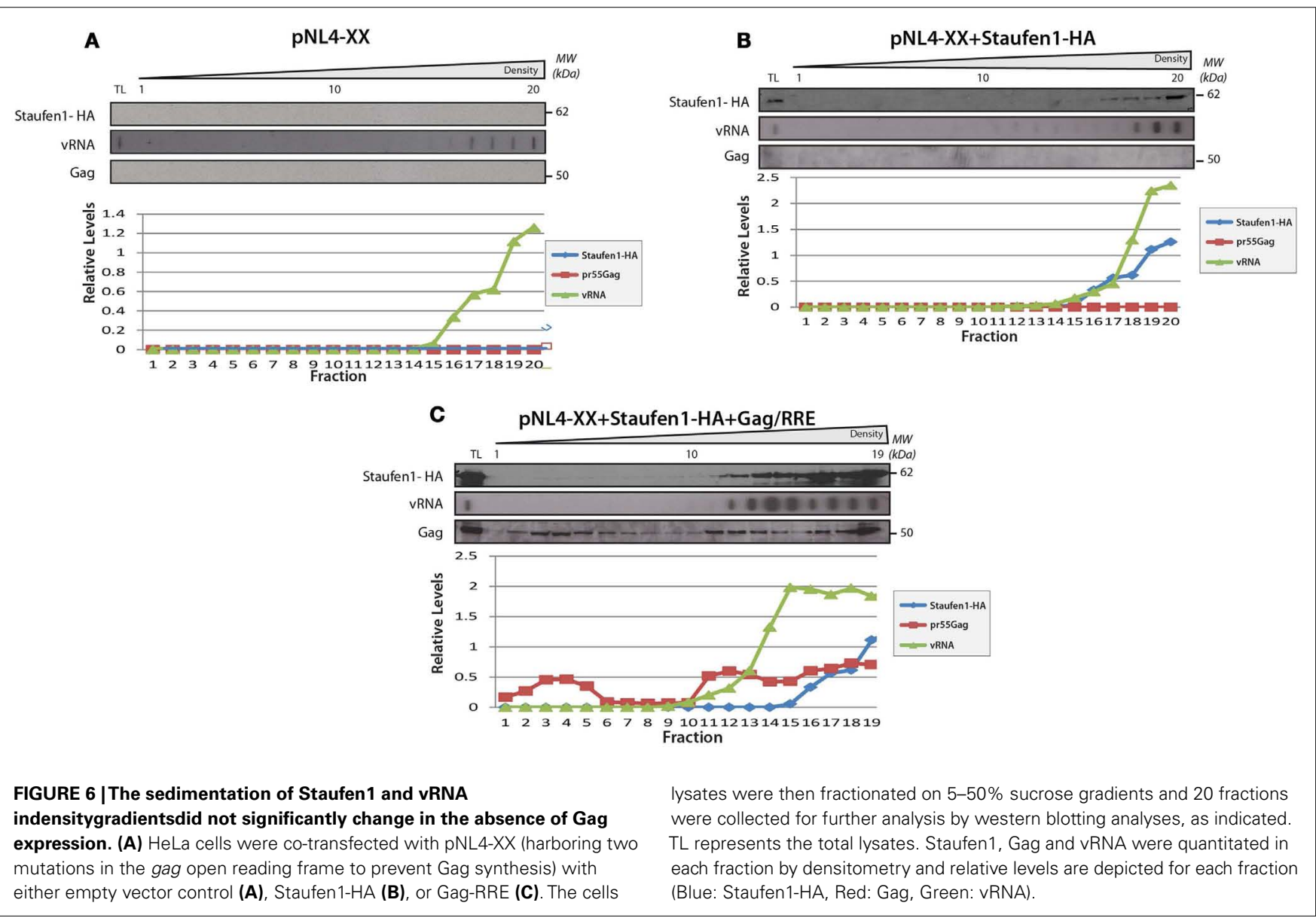



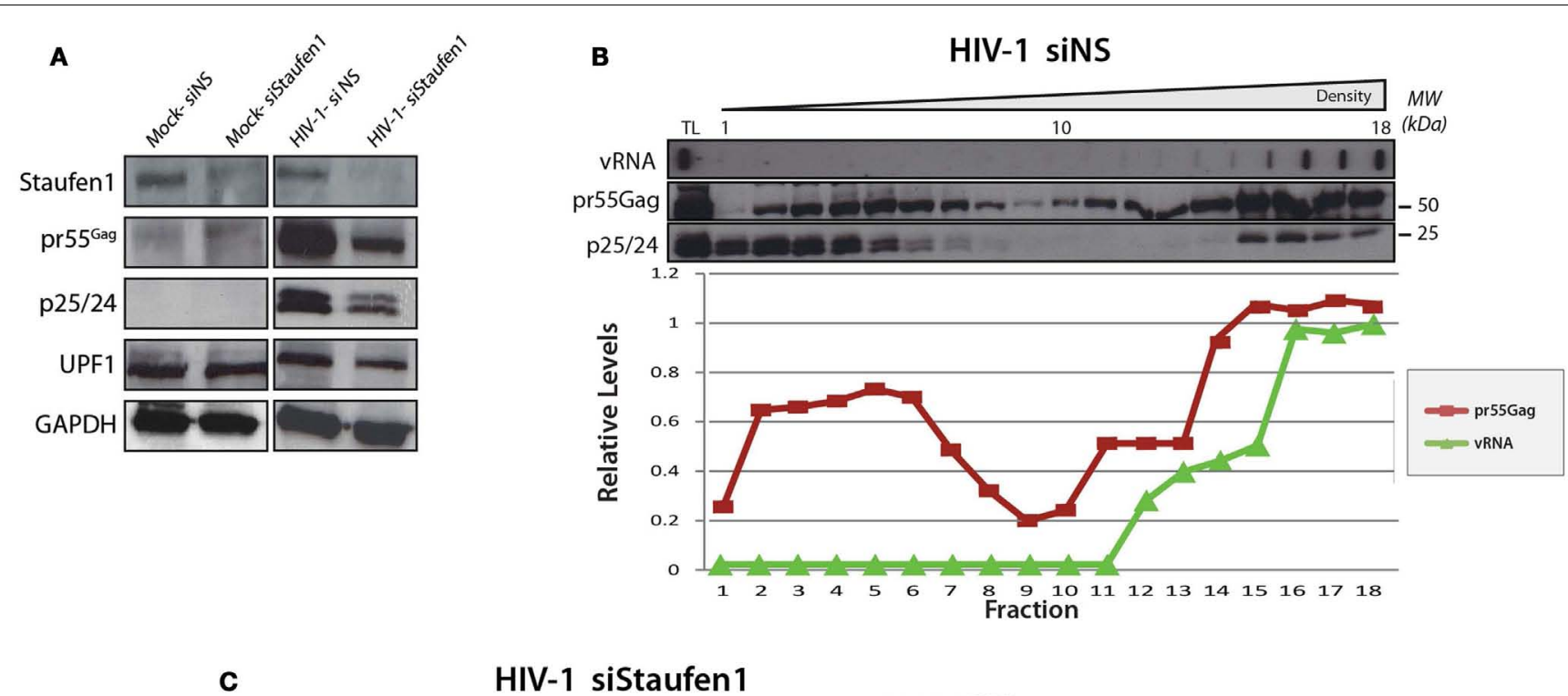

HIV-1 siStaufen 1

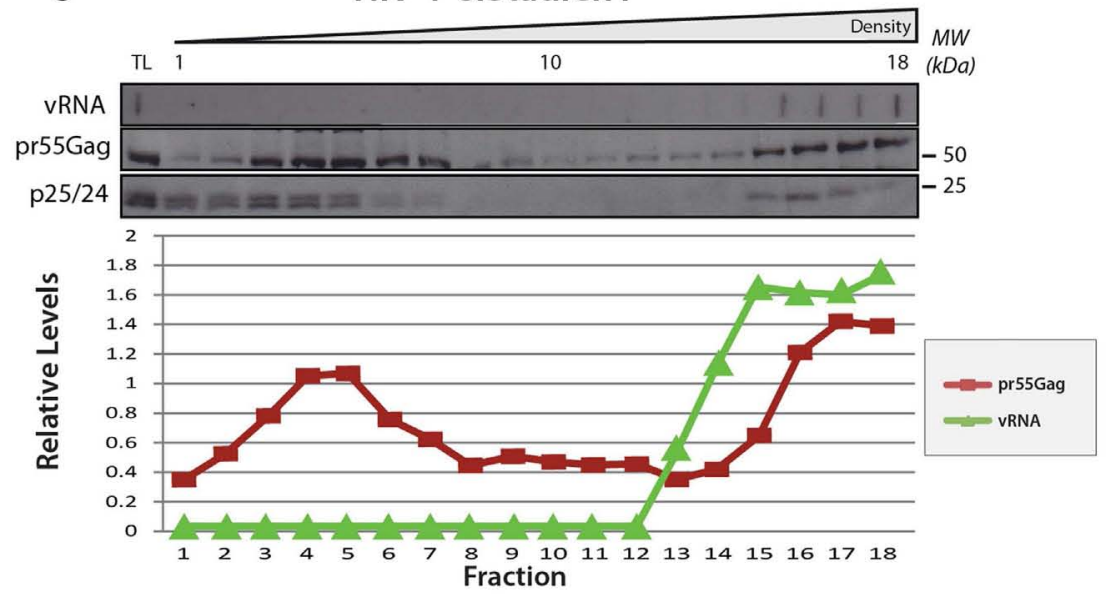

FIGURE 7 | The relative levels of Gag in light and dense gradient fractions are modulatedin Staufen1-depleted cells. HeLa cells were mock transfected or co-transfected with pNL4-3 with either non-silencing control siRNA (siNS) or a siRNA to deplete endogenous Staufen1 (siStaufen1) and were harvested and lysed $36 \mathrm{~h}$ later and analyzed by western blotting. Corresponding expression levels for Staufen1, Gag, UPF1 and GAPDH proteins are shown in (A). The cell lysates from siNS-treated (B) and siStaufen1-treated (C) cells were fractionated on 5-50\% sucrose gradients and 19-20 fractions were collected for further analysis by western blotting, as indicated. TL represents the total lysates. HIV-1 viral genomic RNA (9 kb, vRNA) was assessed in each fraction by slot blot analysis. Staufen1, Gag and vRNA were quantitated in each fraction by densitometry and relative levels are depicted for each fraction (Blue: Staufen1-HA, Red: Gag, Green: vRNA). similar-sized RNPs rather than the assembly of a supraphysiologic RNP (Abrahamyan et al., 2010).

\section{DISCUSSION}

The combination of TAP and mass spectrometry has proven to be reliable for the characterization of different protein complexes (reviewed in Xu et al., 2010) including those containing HIV-1 Gag, UPF1 and Staufen1 (Schell et al., 2003; Brendel et al., 2004; Villace et al., 2004; Roy et al., 2006). Here we provide deeper insights into the impact of HIV-1 expression on the composition of Staufen1 RNPs.

While the analyses performed here detected almost all of the previously characterized proteins characterized as components of Staufen1 RNPs (Brendel et al., 2004; Villace et al., 2004), they also revealed that the protein composition of the particles was influenced by the presence of HIV-1. In addition to the viral gene products, Gag, Gag/Pol, Env and Nef, which are all incorporated into Staufen 1 RNPs in the presence of HIV-1, generally the number of proteins in the Staufen 1 RNP was enhanced in the presence of HIV-1 (Figure 3; Table 1; Tables S1 and S2 in Supplementary Material). In addition, HIV-1-mediated an increase in the amounts of several other host proteins that were found in smaller amounts in Staufen 1-containing RNPs isolated from uninfected 293T cells (Figure 2A). The signal intensities of UPF1, eF1 $\alpha$, ribosomal protein L7a and RHA, for example, were approximately threefold greater in western blotting experiments in the presence of HIV1. Endogenous Staufen 1 was also recruited to a higher degree to the complexes isolated from HIV-1-expressing cells (Figure 2A, 
top panels). This HIV-1-mediated modulation in protein composition of the Staufen1 RNA was indeed selective since equal quantities of several other proteins, such as IMP1, ABCE1 and UPF3 were found between the two treatment groups. The changes to the Staufen 1 protein environment described here could invariably be mediated by the presence of the four viral proteins (Gag, Gag/Pol, Env and Nef) and the vRNA within the Staufen1 HIV-1 RNP, thereby recruiting and enriching for a number of host factors. Consistently, Gag can recruit Staufen 1 and other host factors (Milev et al., 2010). When this analysis was performed in Jurkat $\mathrm{T}$ cell lines, we did not observe some of the same changes to the abundance of proteins (e.g., TDP-43) as judged in western blots (Figure 2C). This could possibly be due to lower transfection efficiencies, or more likely, because the compactness of the cytoplasm in Jurkat $\mathrm{T}$ cells and the relatively shorter intracellular distances in these mononuclear cells might restrict the protein content of Staufen1 RNPs in general. Overall, it will be important to analyze further the possible functions of the unique proteins found in Staufen1 HIV-1 RNPs and their effects on HIV-1 replication.

\section{CONSTITUENTS OF STAUFEN1 RNPS INVOLVED IN mRNA TRANSLATION, TRAFFICKING AND STABILITY}

We identified numerous Staufen1-associated proteins including the small and large ribosomal subunit proteins, translation initiation and elongation factors, tRNA synthetases, some of which are involved in RNA trafficking RNPs (Carson et al., 2008). Most of these proteins were common components that were identified in both native Staufen1 and Staufen1 HIV-1 RNPs as it was in the cases of eIF3 $\alpha$ and eIF4A1 (Tables S1 and S2 in Supplementary Material). However, eIF3 $\beta$ was only found in native and eIF3 $\varepsilon$ was only detected in Staufen1 HIV-1 RNPs (Table 1; Tables S1 and S2 in Supplementary Material). In the context of the Staufen1 HIV-1 RNPs, their functions in mRNA translation could be potentially enhanced by the presence of the viral proteins and evidence for this is supported in the literature (Jager et al., 2012). For example, Env, influences RPS6 kinase and upregulates mRNA translation (Barcova et al., 1999). Furthermore, HIV-1 Gag and that of other retroviruses can modulate the translation activity of its cognate mRNA (the vRNA; Sonstegard and Hackett, 1996; Anderson and Lever, 2006).

Proteins involved in mRNA stability were also common to both native Staufen 1 and Staufen 1 HIV-1 RNPs including Upf1, Upf3b, IMP1 and FUSE-binding protein (refer to Tables S1 and S2 in Supplementary Material for others), but IMP2 and IMP3 were exclusive to native and to Staufen $1 \mathrm{HIV}-1$ complexes, respectively. Although several of these factors have already been shown to alter HIV-1 gene expression (Ajamian et al., 2008; Zhou et al., 2008), additional work will be needed to determine their roles in Staufen1-containing RNPs. Nevertheless, the presence of these proteins suggests that Staufen1 RNPs are involved in the regulation of mRNA translation and stability of both cellular and viral mRNAs. Many components identified as constituents of stress granules (Ohn et al., 2008) were also observed in Staufen1 RNPs including Staufen 1 itself, several RNA helicases, translation factors (eIF3, eEF1), IMP1 and ribosomal proteins (Table S2 in Supplementary Material) and their presence or sequestration could be implicated in the abrogation of this stress response in HIV-1- and other virus-infected cells (Abrahamyan et al., 2010; Ruggieri et al., 2012).

\section{STAUFEN1 RNPS: IMPLICATIONS IN TRANSCRIPTION, SPLICING AND mRNA NUCLEAR RETENTION?}

Staufen1 RNP also contain a number of proteins implicated in nuclear RNA quality control, a role we have previously characterized for UPF1 (Ajamian et al., 2008). We detected several predominantly nuclear proteins in native Staufen 1 and Staufen 1 HIV-1 RNPs such as nucleolin (NCL), hnRNPU and RNA helicase (RHA or DDX9; Brendel et al., 2004; Villace et al., 2004) and several transcription and splicing factors as common elements in both control and HIV-1 Staufen1 RNPs (Tables S1 and S2 in Supplementary Material), but there were also significant differences. Staufen 1 HIV-1 RNPs appeared to be enriched in splicing factors, RNA helicases and hnRNPs (refer to Table 1) that are specifically co-opted by HIV-1 and have established roles in HIV-1 replication (Caputi et al., 1999; Jeang and Yedavalli, 2006; Levesque et al., 2006; Lund et al., 2012). The NF- $\kappa \mathrm{B}$ repressing factor (NRF), for instance, binds to a specific negative regulatory element within the HIV-1 LTR and regulates transcription initiation and elongation (Dreikhausen et al., 2005). Two other RNA- and DNA-binding proteins SFPQ (PSF) and Non-POU domain-containing octamerbinding protein (NONO) act in the context of a heterodimer and play essential roles in the transcriptional regulation and in the pre-mRNA splicing. As well, both proteins play a role in HIV1 replication by binding, with high affinity, the instability (INS) regions in HIV-1 gag mRNA suggesting a role in RNA stability or translation (Zolotukhin et al., 2003). Importantly, NONO and PSF form a complex with another common Staufen 1 component, nuclear matrix protein Matrin 3, as described above (Zhang and Carmichael, 2001; DeCerbo and Carmichael, 2005). Since Staufen 1 can shuttle between the nucleus and cytoplasm (Martel et al., 2006), these potential associations represent potential therapeutic targets in the context of the transporting Staufen1 RNP.

\section{STAUFEN1 RNPS FACTORS INVOLVED IN GENERAL METABOLISM AND CHOLESTEROL BIOGENESIS}

Surprisingly and exclusive to Staufen 1 HIV-1 RNPs, we detected phosphatidylserine synthase 1 (PTDSS1), long-chain-fatty-acidCoA ligase 3 (ACSL3) and 7-dehydrocholesterol reductase (DHCR7), the latter catalyzing the generation of cholesterol (Table 1). Gag's interaction with Staufen1 on cholesterol-rich membranes could suggest a functional implication in cellular cholesterol biogenesis (Milev et al., 2010) in that rerouting cholesterolrich membranes toward the periphery promotes virus release and infectivity (Liao et al., 2001; Tang et al., 2009; Coleman et al., 2012). Likewise, Nef was also detected in Staufen1 HIV-1 RNPs and this viral protein could also influence assembly and trafficking since it induces cholesterol biosynthesis genes (Table 1; Zheng et al., 2003; van't Wout et al., 2005). These findings favor the idea that the processes of cholesterol biosynthesis, the formation of lipid rafts and the trafficking of viral components might be associated to Staufen1-containing complexes.

STAUFEN1-BINDING PARTNERS INVOLVED IN VESICULAR TRAFFICKING We identified multiple proteins that regulate vesicle biogenesis and trafficking within Staufen1 RNPs ( \pm HIV-1), with twice the 
number of proteins with related functions when HIV-1 was expressed. Several common components were detected and known to be involved in the intracellular vesicular transport between the plasma membrane, endoplasmic reticulum and Golgi membranes including the coatomer subunit alpha (COPA; Beck et al., 2009), vesicle-fusing ATPase (NSF; Zhao et al., 2007) and adaptor protein AP-3S1 (sigma subunit; Tables S1 and S2 in Supplementary Material). The coatomer subunit zeta-1 (COPZ1), ADP-ribosylation factors ARF4 and ARF6, several Rab-related proteins (Rab-5C, -8A and -10), adaptor proteins AP-2M1 (mu subunit), AP-3D1 (delta subunit), which importantly, interact with Nef and Env (i.e., AP-2, mu; Boge et al., 1998; Craig et al., 2000) and Gag (i.e., AP-2, mu; AP-3, delta; Batonick et al., 2005; Dong et al., 2005) all uniquely associated to the Staufen 1 HIV-1 RNPs (Table 1). We also identified a putative YXXØ (where $\varnothing$ is a bulky hydrophobic residue) sorting signal in the dsRBD3 of Staufen1 (similar to that found in both Gag and Env; Batonick et al., 2005) that may mediate the mu subunit binding. Likewise, the existence of several di-leucine sorting motifs in Staufen 1 could mediate binding to COP1 beta (Ohno et al., 1995; Rapoport et al., 1998). These observations support the notion that the mRNA/HIV-1 vRNA transport pathways are coupled with organized vesicular trafficking in cells (Cohen, 2005; Baumann et al., 2012), that is strengthened by several recent observations that vRNA traffics on endosomal membranes during HIV-1 egress and assembly (Lehmann et al., 2009; Molle et al., 2009).

Most of the biochemical evidence points to a role for Staufen1 RNPs in vRNA fate. The co-sedimentation of several components with Staufen1, using the available antibodies, reveals coassociations that are likely to be functionally relevant in this context and important for HIV-1-mediated disease (e.g., Tosar et al., 2012). Indeed, several of these associations have been characterized previously, for example those that have been characterized between Gag and ABCE1, Staufen1, UPF1, AUF1, IMP1 and RNA helicases. These RNPs appear to be static in size (Figure 6), but are mobile since they can aggregate in clusters when Staufen 1 is in limiting supply (Abrahamyan et al., 2010). The disruption of all of these protein complexes upon RNAse A treatment reveals the dependence on viral and/or cellular RNA but also indicates

\section{REFERENCES}

Abrahamyan, L. G., Chatel-Chaix, L., Ajamian, L., Milev, M. P., Monette, A., Clement, J. F., et al. (2010). Novel Staufen 1 ribonucleoproteins prevent formation of stress granules but favor encapsidation of HIV1 genomic RNA. J. Cell. Sci. 123, 369-383.

Adachi, A., Gendelman, H. E., Koenig, S., Folks, T., Willey, R., Rabson, A., et al. (1986). Production of acquired immunodeficiency syndrome-associated retrovirus in human and nonhuman cells transfected with an infectious molecular clone. J. Virol. 59, 284-291.

Ajamian, L., Abrahamyan, L., Milev, M., Ivanov, P. V., Kulozik, A. E., Gehring, N. H., et al. (2008). Unexpected roles

that the targeting of RNA-related phenomena will be a suitable therapeutic approach in the future (Radi et al., 2012).

\section{CONCLUSION}

Staufen 1 has multiple roles during HIV-1 replication including one in Gag multimerization and another in genomic RNA encapsidation. The present study applied tandem affinity immunopurification techniques coupled with mass spectrometry to characterize the composition of Staufen1 RNPs in HIV-1-expressing cells. Our results demonstrate that HIV-1 induces substantial changes to the composition of cellular Staufen1 RNPs. The identification of the associated host and viral factors to the Staufen 1 RNP will contribute to a better understanding of how HIV-1 co-opts subcellular RNPs and machineries to achieve intracellular trafficking, efficient gene expression and the correct localization and fate of its genomic RNA.

\section{AUTHORS' CONTRIBUTIONS}

Miroslav P. Milev, Mukunthan Ravichandran and Andrew J. Mouland designed the experiments, analyzed the data and drafted the manuscript; Miroslav P. Milev and Mukunthan Ravichandran performed the experiments; Morgan F. Khan and David C. Schriemer performed LC-MS/MS analyses, peptide and protein identifications and analyzed the mass spectrometry results. All authors edited and approved the final manuscript.

\section{ACKNOWLEDGMENTS}

We thank Juan Ortin, Luc DesGroseillers, Chris Brown, JensLykke Andersen, Rob Schneider, Finn Nielsen, William Rigby and Jaisri Lingappa for providing constructs and antibodies and Lara Ajamian, Fernando Valiente-Echeverria and Marie-Joelle Miron for comments on the manuscript. Andrew J. Mouland is a recipient of a Fraser, Monat, McPherson McGill University Scholarship and this research was supported by the Canadian Institutes of Health Research (\#MOP-38111) to Andrew J. Mouland.

\section{SUPPLEMENTARY MATERIAL}

The Supplementary Material (Tables S1 and S2) for this article can be found online at: http://www.frontiersin.org/Virology/10.3389/ fmicb.2012.00367/abstract

Askjaer, P., Jensen, T. H., Nilsson, J., Englmeier, L., and Kjems, J. (1998). The specificity of the CRM1-Rev nuclear export signal interaction is mediated by RanGTP. J. Biol. Chem. 273, 33414-33422.

Babst, M., Odorizzi, G., Estepa, E. J., and Emr, S. D. (2000). Mammalian tumor susceptibility gene 101 (TSG101) and the yeast homologue, Vps23p, both function in late endosomal trafficking. Traffic 1, 248-258.

Barcova, M., Speth, C., Kacani, L., Uberall, F., Stoiber, H., and Dierich, M. P. (1999). Involvement of adenylate cyclase and p70 (S6)kinase activation in IL-10 upregulation in human monocytes by gp41 envelope protein of human immunodeficiency virus type 1 . Pflugers Arch. 437, 538-546.

Batonick, M., Favre, M., Boge, M., Spearman, P., Honing, S., and Thali, M. (2005). Interaction of HIV-1 Gag with the clathrin-associated adaptor AP-2. Virology 342, 190-200.

Baumann, S., Pohlmann, T., Jungbluth, M., Brachmann, A., and Feldbrugge, M. (2012). Kinesin-3 and dynein mediate microtubule-dependent co-transport of mRNPs and endosomes. J. Cell. Sci. 125, 2740-2752.

J. A., and Chen, I. S. (1990) Characterization and expression of novel singly spliced RNA species of human immunodeficiency virus type 1. J. Virol. 64, 4585-4588.
Beck, R., Rawet, M., Wieland, F. T., and Cassel, D. (2009). The COPI system: molecular mechanisms and function. FEBS Lett. 583 , 2701-2709. 
Belgrader, P., Dey, R., and Berezney, R. (1991). Molecular cloning of matrin 3. A 125-kilodalton protein of the nuclear matrix contains an extensive acidic domain. J. Biol. Chem. 266, 9893-9899.

Beriault, V., Clement, J. F., Levesque, K., Lebel, C., Yong, X.,Chabot, B., et al. (2004). A late role for the association of hnRNP A2 with the HIV-1 hnRNP A2 response elements in genomic RNA, Gag, and Vpr localization. J. Biol. Chem. 279, 44141-44153.

Boge, M., Wyss, S., Bonifacino, J. S., and Thali, M. (1998). A membrane-proximal tyrosine-based signal mediates internalization of the HIV-1 envelope glycoprotein via interaction with the AP-2 clathrin adaptor. J. Biol. Chem. 273, 15773-15778.

Bouyac, M., Courcoul, M., Bertoia, G., Baudat, Y., Gabuzda, D., Blanc, D., et al. (1997). Human immunodeficiency virus type $1 \mathrm{Vif}$ protein binds to the Pr55Gag precursor. J. Virol. 71, 9358-9365.

Brass, A. L., Dykxhoorn, D. M., Benita, Y., Yan, N., Engelman, A., Xavier, R. J., et al. (2008). Identification of host proteins required for HIV infection through a functional genomic screen. Science 319, 921-926.

Brendel, C., Rehbein, M., Kreienkamp, H. J., Buck, F., Richter, D., and Kindler, S. (2004). Characterization of Staufen 1 ribonucleoprotein complexes. Biochem. J. 384, 239-246.

Butsch, M., and Boris-Lawrie, K. (2002). Destiny of unspliced retroviral RNA: ribosome and/or virion? J. Virol. 76, 3089-3094.

Cantin, R., Methot, S., and Tremblay, M. J. (2005). Plunder and stowaways: incorporation of cellular proteins by enveloped viruses. J. Virol. 79, 6577-6587.

Caputi, M., Mayeda, A., Krainer, A. R., and Zahler, A. M. (1999). hnRNP $\mathrm{A} / \mathrm{B}$ proteins are required for inhibition of HIV-1 pre-mRNA splicing. EMBO J. 18, 4060-4067.

Carson, J. H., Gao, Y., Tatavarty, V., Levin, M. K., Korza, G., Francone, V. P., et al. (2008). Multiplexed RNA trafficking in oligodendrocytes and neurons. Biochim. Biophys. Acta 1779, 453-458.

Chatel-Chaix, L., Abrahamyan, L., Frechina, C., Mouland, A. J., and Desgroseillers, L. (2007). The host protein Staufen1 participates in human immunodeficiency virus type 1 assembly in live cells by influencing pr55Gag multimerization. J. Virol. 81, 6216-6230.
Chatel-Chaix, L., Boulay, K., Mouland, A. J., and Desgroseillers, L. (2008). The host protein Staufen1 interacts with the Pr55Gag zinc fingers and regulates HIV-1 assembly via its $\mathrm{N}$-terminus. Retrovirology 5, 41.

Chatel-Chaix, L., Clement, J. F., Martel, C., Beriault, V., Gatignol, A., Desgroseillers, L., et al. (2004). Identification of Staufen in the human immunodeficiency virus type 1 Gag ribonucleoprotein complex and a role in generating infectious viral particles. Mol. Cell. Biol. 24, 2637-2648.

Chertova, E., Chertov, O., Coren, L. V., Roser, J. D., Trubey, C. M., Bess, J. W. Jr., et al. (2006). Proteomic and biochemical analysis of purified human immunodeficiency virus type 1 produced from infected monocyte-derived macrophages. $J$. Virol. 80, 9039-9052.

Chiu, Y. L., Witkowska, H. E., Hall, S. C., Santiago, M., Soros, V. B., Esnault, C., et al. (2006). High-molecular-mass APOBEC3G complexes restrict Alu retrotransposition. Proc. Natl. Acad. Sci. U.S.A. 103, 15588-15593.

Cimarelli, A., and Luban, J. (1999). Translation elongation factor 1alpha interacts specifically with the human immunodeficiency virus type 1 Gag polyprotein. J. Virol. 73 , 5388-5401.

Clever, J., Sassetti, C., and Parslow, T. G. (1995). RNA secondary structure and binding sites for gag gene products in the $5^{\prime}$ packaging signal of human immunodeficiency virus type 1. J. Virol. 69, 2101-2109.

Cochrane, A. W., Mcnally, M. T., and Mouland, A. J. (2006). The retrovirus RNA trafficking granule: from birth to maturity. Retrovirology 3,18 .

Cohen, R. S. (2005). The role of membranes and membrane trafficking in RNA localization. Biol. Cell 97, 5-18.

Coleman, E. M., Walker, T. N., and Hildreth, J. E. (2012). Loss of Niemann Pick type $\mathrm{C}$ proteins 1 and 2 greatly enhances HIV infectivity and is associated with accumulation of HIV Gag and cholesterol in late endosomes/lysosomes. Virol. J. 9, 31.

Craig, H. M., Reddy, T. R., Riggs, N. L., Dao, P. P., and Guatelli, J. C. (2000). Interactions of HIV-1 nef with the mu subunits of adaptor protein complexes 1,2 , and 3 : role of the dileucine-based sorting motif. Virology 271, 9-17.

de Lucas, S., Peredo, J., Marion, R. M., Sanchez, C., and Ortin, J. (2010). Human Staufenl protein interacts with influenza virus ribonucleoproteins and is required for efficient virus multiplication. $J$. Virol. 84, 7603-7612.

DeCerbo, J., and Carmichael, G. G. (2005). Retention and repression: fates of hyperedited RNAs in the nucleus. Curr. Opin. Cell Biol. 17, 302-308.

Doma, M. K., and Parker, R. (2007). RNA quality control in eukaryotes. Cell 131, 660-668.

Dong, X., Li, H., Derdowski, A., Ding, L., Burnett, A., Chen, X., et al. (2005) AP-3 directs the intracellular trafficking of HIV-1 Gag and plays a key role in particle assembly. Cell 120 663-674.

Dooher, J. E., Schneider, B. L., Reed, J. C., and Lingappa, J. R. (2007). Host ABCE1 is at plasma membrane HIV assembly sites and its dissociation from Gag is linked to subsequent events of virus production. Traffic 8 195-211.

Doria, M., Neri, F., Gallo, A., Farace, M. G., and Michienzi, A. (2009). Editing of HIV-1 RNA by the doublestranded RNA deaminase ADAR1 stimulates viral infection. Nucleic Acids Res. 37, 5848-5858.

Dreikhausen, U., Hiebenthal-Millow, K., Bartels, M., Resch, K., and Nourbakhsh, M. (2005). NF-kappaBrepressing factor inhibits elongation of human immunodeficiency virus type 1 transcription by DRB sensitivity-inducing factor Mol. Cell. Biol. 25, 7473-7483.

Falcon, A. M., Fortes, P., Marion, R. M., Beloso, A., and Ortin, J. (1999). Interaction of influenza virus NS1 protein and the human homologue of Staufen in vivo and in vitro. Nucleic Acids Res. 27, 2241-2247.

Fassati, A., Gorlich, D., Harrison, I., Zaytseva, L., and Mingot, J. M. (2003). Nuclear import of HIV1 intracellular reverse transcription complexes is mediated by importin 7. EMBO J. 22, 3675-3685.

Fierro-Monti, I., and Mathews, M. B. (2000). Proteins binding to duplexed RNA: one motif, multiple functions. Trends Biochem. Sci. 25, 241-246.

Freed, E. O. (1998). HIV-1 gag proteins: diverse functions in the virus life cycle. Virology 251, 1-15.

Freed, E. O. (2001). HIV-1 replication. Somat. Cell Mol. Genet. 26, 13-33.

Furic, L., Maher-Laporte, M., and Desgroseillers, L. (2008). A genomewide approach identifies distinct but overlapping subsets of cellular mRNAs associated with Staufen1and Staufen2-containing ribonucleoprotein complexes. RNA 14 324-335.
Garrus, J. E., Von Schwedler, U. K., Pornillos, O. W., Morham, S. G., Zavitz, K. H., Wang, H. E., et al. (2001). Tsg101 and the vacuolar protein sorting pathway are essential for HIV-1 budding. Cell 107, 55-65.

Goff, S. P. (2007). Host factors exploited by retroviruses. Nat. Rev. Microbiol. 5, 253-263.

Gurer, C., Cimarelli, A., and Luban, J. (2002). Specific incorporation of heat shock protein 70 family members into primate lentiviral virions. J. Virol. 76, 4666-4670.

Hadian, K., Vincendeau, M., Mäusbacher, N., Nagel, D., Hauck, S. M. Ueffing, M., et al. (2009). Identification of a heterogeneous nuclear ribonucleoprotein-recognition region in the HIV Rev protein. J. Biol. Chem. 284, 33384-33391.

Harris, D., Zhang, Z., Chaubey, B., and Pandey, V. N. (2006). Identification of cellular factors associated with the $3^{\prime}$-nontranslated region of the hepatitis C virus genome. Mol. Cell Proteomics 5, 1006-1018.

Ho, D. D., Neumann, A. U., Perelson, A. S., Chen, W., Leonard, J. M., and Markowitz, M. (1995). Rapid turnover of plasma virions and CD4 lymphocytes in HIV-1 infection. Nature 373, 123-126.

Jacks, T., Power, M. D., Masiarz, F. R., Luciw, P. A., Barr, P. J., and Varmus, H. E. (1988). Characterization of ribosomal frameshifting in HIV1 gag-pol expression. Nature 331, 280-283.

Jager, S., Cimermancic, P., Gulbahce, N., Johnson, J. R., Mcgovern, K. E., Clarke, S. C., et al. (2012). Global landscape of HIV-human protein complexes. Nature 481, 365-370.

Jeang, K. T., and Yedavalli, V. (2006). Role of RNA helicases in HIV-1 replication. Nucleic Acids Res. 34, 4198-4205.

Jonson, L., Vikesaa, J., Krogh, A., Nielsen, L. K., Hansen, T., Borup, R., et al. (2007). Molecular composition of IMP1 ribonucleoprotein granules. Mol. Cell Proteomics 6, 798-811.

Kemler, I., Meehan, A., and Poeschla, E. M. (2010). Live-cell coimaging of the genomic RNAs and Gag proteins of two lentiviruses. J. Virol. 84, 6352-6366.

Khan, M. A., Kao, S., Miyagi, E., Takeuchi, H., Goila-Gaur, R., Opi, S., et al. (2005). Viral RNA is required for the association of APOBEC3G with human immunodeficiency virus type 1 nucleoprotein complexes. J. Virol. 79, 5870-5874. 
Khorchid, A., Halwani, R., Wainberg, M. A., and Kleiman, L. (2002). Role of RNA in facilitating Gag/Gag-Pol interaction. J. Virol. 76, 4131-4137.

Kiebler, M. A., and DesGroseillers, L. (2000). Molecular insights into mRNA transport and local translation in the mammalian nervous system. Neuron 25, 19-28.

Kiebler, M. A., Hemraj, I., Verkade, P., Kohrmann, M., Fortes, P., Marion, R. M., et al. (1999). The mammalian staufen protein localizes to the somatodendritic domain of cultured hippocampal neurons: implications for its involvement in mRNA transport. J. Neurosci. 19, 288-297.

Kim, Y. K., Furic, L., Desgroseillers, L., and Maquat, L. E. (2005). Mammalian Staufen1 recruits Upf1 to specific mRNA $3^{\prime}$ UTRs so as to elicit mRNA decay. Cell 120, 195-208.

Kim, Y. K., Furic, L., Parisien, M., Major, F., Desgroseillers, L., and Maquat, L. E. (2007). Staufen 1 regulates diverse classes of mammalian transcripts. EMBO J. 26, 2670-2681.

Klein, K. C., Reed, J. C., and Lingappa, J. R. (2007). Intracellular destinies: degradation, targeting, assembly, and endocytosis of HIV Gag. AIDS Rev. 9, 150-161.

Komano, J., Futahashi, Y., Urano, E., Miyauchi, K., Murakami, T., Matsuda, Z., et al. (2005). The interaction of HIV-1 with the host factors. Jpn. J. Infect. Dis. 58, 125-130.

Komano, J., Miyauchi, K., Matsuda, Z., and Yamamoto, N. (2004). Inhibiting the Arp $2 / 3$ complex limits infection of both intracellular mature vaccinia virus and primate lentiviruses. Mol. Biol. Cell 15, 5197-5207.

Kondo, E., Mammano, F., Cohen, E. A., and Gottlinger, H. G. (1995). The p6gag domain of human immunodeficiency virus type 1 is sufficient for the incorporation of $\mathrm{Vpr}$ into heterologous viral particles. J. Virol. 69, 2759-2764.

Kozak, S. L., Marin, M., Rose, K. M., Bystrom, C., and Kabat, D. (2006). The anti-HIV-1 editing enzyme APOBEC3G binds HIV1 RNA and messenger RNAs that shuttle between polysomes and stress granules. J. Biol. Chem. 281, 29105-29119.

Lavallee, C., Yao, X. J., Ladha, A., Gottlinger, H., Haseltine, W. A., and Cohen, E. A. (1994). Requirement of the Pr55gag precursor for incorporation of the $\mathrm{Vpr}$ product into human immunodeficiency virus type 1 viral particles. J. Virol. 68, 1926-1934.

Lee, K., Ambrose, Z., Martin, T. D., Oztop, I., Mulky, A., Julias, J. G., et al. (2010). Flexible use of nuclear import pathways by HIV-1. Cell Host Microbe. 7, 221-233.

Lehmann, M., Milev, M., Abrahamyan, L., Yao, X. J., Pante, N., and Mouland, A. J. (2009). Intracellular transport of human immunodeficiency virus type 1 genomic RNA and viral production are dependent on dynein motor function and late endosome positioning. J. Biol. Chem. 284, 14572-14585.

Lever, A., Gottlinger, H., Haseltine, W., and Sodroski, J. (1989). Identification of a sequence required for efficient packaging of human immunodeficiency virus type 1 RNA into virions. J. Virol. 63, 4085-4087.

Levesque, K., Halvorsen, M., Abrahamyan, L., Chatel-Chaix, L., Poupon, V., Gordon, H., et al. (2006). Trafficking of HIV-1 RNA is mediated by heterogeneous nuclear ribonucleoprotein A2 expression and impacts on viral assembly. Traffic 7, 1177-1193.

Liao, Z., Cimakasky, L. M., Hampton, R., Nguyen, D. H., and Hildreth, J. E. (2001). Lipid rafts and hiv pathogenesis: host membrane cholesterol is required for infection by hiv type 1. AIDS Res. Hum. Retroviruses 17, 1009-1019.

Limou, S., Le Clerc, S., Coulonges, C., Carpentier, W., Dina, C., Delaneau, O., et al. (2009). Genome-wide association study of an AIDSnonprogression cohort emphasizes the role played by HLA genes (ANRS Genomewide Association Study 02). J. Infect. Dis. 199, 419-426.

Lindwasser, O. W., Chaudhuri, R., and Bonifacino, J. S. (2007). Mechanisms of CD4 downregulation by the Nef and $\mathrm{Vpu}$ proteins of primate immunodeficiency viruses. Curr. Mol. Med. 7, 171-184.

Lingappa, J. R., Dooher, J. E., Newman, M. A., Kiser, P. K., and Klein, K. C. (2006). Basic residues in the nucleocapsid domain of Gag are required for interaction of HIV-1 gag with ABCE1 (HP68), a cellular protein important for HIV-1 capsid assembly. J. Biol. Chem. 281, 3773-3784

Lund, N., Milev, M. P., Wong, R., Sanmuganantham, T., Woolaway, K., Chabot, B., et al. (2012). Differential effects of hnRNP D/AUF1 isoforms on HIV-1 gene expression. Nucleic Acids Res. 40, 3663-3675.

Macchi, P., Kroening, S., Palacios, I. M., Baldassa, S., Grunewald, B., Ambrosino, C., et al. (2003). Barentsz, a new component of the Staufen-containing ribonucleoprotein particles in mammalian cells, interacts with Staufen in an RNAdependent manner. J. Neurosci. 23 , 5778-5788.

Martel, C., Dugre-Brisson, S., Boulay, K. Breton, B., Lapointe, G., Armando, S., et al. (2010). Multimerization of Staufen 1 in live cells. RNA 16 585-597.

Martel, C., Macchi, P., Furic, L., Kiebler, M. A., and Desgroseillers, L. (2006). Staufen 1 is imported into the nucleolus via a bipartite nuclear localization signal and several modulatory determinants. Biochem. J. 393 245-254.

Milev, M. P., Brown, C. M., and Mouland, A. J. (2010). Live cell visualization of the interactions between HIV-1 Gag and the cellular RNAbinding protein Staufen1. Retrovirology 7,41 .

Molle, D., Segura-Morales, C., Camus, G., Berlioz-Torrent, C., Kjems, J., Basyuk, E., et al. (2009). Endosomal trafficking of HIV-1 gag and genomic RNAs regulates viral egress. J. Biol. Chem. 284, 19727-19743.

Monette, A., Ajamian, L., Lopez-Lastra M., and Mouland, A. J. (2009). Human immunodeficiency virus type 1 (HIV-1) induces the cytoplasmic retention of heterogeneous nuclear ribonucleoprotein A1 by disrupting nuclear import: implications for HIV-1 gene expression. J. Biol. Chem. 284, 31350-31362.

Mouland, A. J., Coady, M., Yao, X. J., and Cohen, E. A. (2002). Hypophosphorylation of poly(A) polymerase and increased polyadenylation activity are associated with human immunodeficiency virus type 1 Vpr expression. Virology 292, 321-330.

Mouland, A. J., Mercier, J., Luo, M., Bernier, L., Desgroseillers, L., and Cohen, E. A. (2000). The double-stranded RNA-binding protein Staufen is incorporated in human immunodeficiency virus type 1: evidence for a role in genomic RNA encapsidation. J. Virol. 74 5441-5451.

Mouland, A. J., Xu, H., Cui, H., Krueger, W., Munro, T. P., Prasol, M., et al. (2001). RNA trafficking signals in human immunodeficiency virus type 1. Mol. Cell. Biol. 21, 2133-2143.
Nathans, R., Chu, C. Y., Serquina, A. K., Lu, C. C., Cao, H., and Rana, T. M. (2009). Cellular microRNA and $\mathrm{P}$ bodies modulate host-HIV-1 interactions. Mol. Cell 34, 696-709.

Ohn, T., Kedersha, N., Hickman, T., Tisdale, S., and Anderson, P. (2008). A functional RNAi screen links OGlcNAc modification of ribosomal proteins to stress granule and processing body assembly. Nat. Cell Biol. 10, 1224-1231.

Ohno, H., Stewart, J., Fournier, M. C., Bosshart, H., Rhee, I., Miyatake, S., et al. (1995). Interaction of tyrosine-based sorting signals with clathrin-associated proteins. Science 269, 1872-1875.

Ono, A., Ablan, S. D., Lockett, S. J., Nagashima, K., and Freed, E. O. (2004). Phosphatidylinositol $(4,5)$ bisphosphate regulates HIV-1 Gag targeting to the plasma membrane. Proc. Natl. Acad. Sci. U.S.A. 101, 14889-14894.

Ott, D. E. (2002). Potential roles of cellular proteins in HIV-1. Rev. Med. Virol. 12, 359-374.

Ott, D. E. (2008). Cellular proteins detected in HIV-1. Rev. Med. Virol. 18, 159-175.

Ou, S. H., Wu, F., Harrich, D., GarciaMartinez, L. F., and Gaynor, R. B. (1995). Cloning and characterization of a novel cellular protein, TDP-43, that binds to human immunodeficiency virus type 1 TAR DNA sequence motifs. J. Virol. 69, 3584-3596.

Palacios, I. M., Gatfield, D., St Johnston, D., and Izaurralde, E. (2004). An eIF4AIII-containing complex required for mRNA localization and nonsense-mediated mRNA decay. Nature 427, 753-757.

Patel, G. P., and Bag, J. (2006). IMP1 interacts with poly(A)-binding protein (PABP) and the autoregulatory translational control element of PABP-mRNA through the KH III-IV domain. FEBS J. 273, 5678-5690.

Phuphuakrat, A., Kraiwong, R., Boonarkart, C., Lauhakirti, D., Lee, T. H., and Auewarakul, P. (2008). Double-stranded RNA adenosine deaminases enhance expression of human immunodeficiency virus type 1 proteins. J. Virol. 82 , 10864-10872.

Pizzato, M., Helander, A., Popova, E. Calistri, A., Zamborlini, A., Palù, G., et al. (2007). Dynamin 2 is required for the enhancement of HIV-1 infectivity by Nef. Proc. Natl. Acad. Sci. U.S.A. 104, 6812-6817.

Poole, E., Strappe, P., Mok, H. P., Hicks, R., and Lever, A. M. (2005). HIV-1 Gag-RNA interaction occurs 
at a perinuclear/centrosomal site; analysis by confocal microscopy and FRET. Traffic 6, 741-755.

Poon, D. T., Chertova, E. N., and Ott, D. E. (2002). Human immunodeficiency virus type 1 preferentially encapsidates genomic RNAs that encode Pr55 (Gag): functional linkage between translation and RNA packaging. Virology 293, 368-378.

Puig, O., Caspary, F., Rigaut, G., Rutz, B., Bouveret, E., Bragado-Nilsson, E., et al. (2001). The tandem affinity purification (TAP) method: a general procedure of protein complex purification. Methods 24, 218-229.

Purcell, D. F., and Martin, M. A. (1993). Alternative splicing of human immunodeficiency virus type 1 mRNA modulates viral protein expression, replication, and infectivity. J. Virol. 67, 6365-6378.

Rackham, O., and Brown, C. M. (2004). Visualization of RNA-protein interactions in living cells: FMRP and IMP1 interact on mRNAs. EMBO J. 23, 3346-3355.

Radi, M., Falchi, F., Garbelli, A., Samuele, A., Bernardo, V., Paolucci, S., et al. (2012). Discovery of the first small molecule inhibitor of human DDX3 specifically designed to target the RNA binding site: towards the next generation HIV-1 inhibitors. Bioorg. Med. Chem. Lett. 22, 2094-2098.

Rapoport, I., Chen, Y. C., Cupers, P., Shoelson, S. E., and Kirchhausen, T. (1998). Dileucine-based sorting signals bind to the beta chain of AP-1 at a site distinct and regulated differently from the tyrosinebased motif-binding site. $E M B O \mathrm{~J}$. $17,2148-2155$

Rasheed, S., Yan, J. S., Lau, A., and Chan, A. S. (2008). HIV replication enhances production of free fatty acids, low density lipoproteins and many key proteins involved in lipid metabolism: a proteomics study. PLoS One 3, e3003.

Ringrose, J. H., Jeeninga, R. E., Berkhout, B., and Speijer, D. (2008). Proteomic studies reveal coordinated changes in T-cell expression patterns upon infection with human immunodeficiency virus type 1. J. Virol. 82, 4320-4330.

Roegiers, F., and Jan, Y. N. (2000). Staufen: a common component of mRNA transport in oocytes and neurons? Trends Cell Biol. 10, 220-224.

Roy, B. B., Hu, J., Guo, X., Russell, R. S., Guo, F., Kleiman, L., et al. (2006). Association of RNA helicase a with human immunodeficiency virus type 1 particles. J. Biol. Chem. 281, 12625-12635.

Ruggieri, A., Dazert, E., Metz, P., Hofmann, S., Bergeest, J. P., Mazur, J., et al. (2012). Dynamic oscillation of translation and stress granule formation mark the cellular response to virus infection. Cell Host Microbe 12, 71-85.

Saunders, L. R., and Barber, G. N. (2003). The dsRNA binding protein family: critical roles, diverse cellular functions. FASEB J. 17, 961-983.

Schell, T., Kocher, T., Wilm, M., Seraphin, B., Kulozik, A. E., and Hentze, M. W. (2003). Complexes between the nonsense-mediated mRNA decay pathway factor human upf1 (up-frameshift protein 1) and essential nonsense-mediated mRNA decay factors in HeLa cells. Biochem. J. 373, 775-783.

Schwartz, S., Felber, B. K., Benko, D. M., Fenyo, E. M., and Pavlakis, G. N. (1990). Cloning and functional analysis of multiply spliced mRNA species of human immunodeficiency virus type 1. J. Virol. 64, 2519-2529.

Sonstegard, T. S., and Hackett, P. B. (1996). Autogenous regulation of RNA translation and packaging by Rous sarcoma virus Pr76gag. J. Virol. 70, 6642-6652.

Sun, Z., Pan, J., Hope, W. X., Cohen, S. N., and Balk, S. P. (1999). Tumor susceptibility gene 101 protein represses androgen receptor transactivation and interacts with $\mathrm{p} 300$. Cancer 86, 689-696.

Syed, F., and McCrae, M. A. (2009). Interactions in vivo between the Vif protein of HIV-1 and the precursor (Pr55 (GAG)) of the virion nucleocapsid proteins. Arch. Virol. 154, 1797-1805.

Tang, Y., Leao, I. C., Coleman, E. M., Broughton, R. S., and Hildreth, J. E. (2009). Deficiency of niemann-pick type C-1 protein impairs release of human immunodeficiency virus type 1 and results in Gag accumulation in late endosomal/lysosomal compartments. $J$. Virol. 83, 7982-7995.

Thomas, M. G., Martinez Tosar, L. J., Loschi, M., Pasquini, J. M., Correale, J., Kindler, S., et al. (2005). Staufen recruitment into stress granules does not affect early mRNA transport in oligodendrocytes. Mol. Biol. Cell 16, 405-420.

Tian, B., Bevilacqua, P. C., EgelmanParente, A., and Mathews, M. B. (2004). The double-stranded-RNAbinding motif: interference and much more. Nat. Rev. Mol. Cell Biol. 5, 1013-1023.
Tosar, L. J., Thomas, M. G., Baez, M. V., Ibanez, I., Chernomoretz, A., and Boccaccio, G. L. (2012). Staufen: from embryo polarity to cellular stress and neurodegeneration. Front. Biosci. (Schol. Ed.) 4, 432-452.

Tsuchiya, N., Fukuda, H., Nakashima, K., Nagao, M., Sugimura, T., and Nakagama, H. (2004). LRP130, a single-stranded DNA/RNA-binding protein, localizes at the outer nuclear and endoplasmic reticulum membrane, and interacts with mRNA in vivo. Biochem. Biophys. Res. Commun. 317, 736-743.

van't Wout, A. B., Swain, J. V., Schindler, M., Rao, U., Pathmajeyan, M. S., Mullins, J. I., et al. (2005). Nef induces multiple genes involved in cholesterol synthesis and uptake in human immunodeficiency virus type 1-infected T cells. J. Virol. 79, 10053-10058.

VerPlank, L., Bouamr, F., Lagrassa, T J., Agresta, B., Kikonyogo, A., Leis, J., et al. (2001). Tsg101, a homologue of ubiquitin-conjugating (E2) enzymes, binds the L domain in HIV type 1 Pr55(Gag). Proc. Natl. Acad. Sci. U.S.A. 98, 7724-7729.

Vidricaire, G., and Tremblay, M. J. (2005). Rab5 and Rab7, but not ARF6, govern the early events of HIV-1 infection in polarized human placental cells. J. Immunol. 175, 6517-6530.

Villace, P., Marion, R. M., and Ortin, J. (2004). The composition of Staufen-containing RNA granules from human cells indicates their role in the regulated transport and translation of messenger RNAs. Nucleic Acids Res. 32, 2411-2420

Vyboh, K., Ajamian, L., and Mouland, A. J. (2012). Detection of viral RNA by fluorescence in situ hybridization (FISH). J. Vis. Exp. 63, e4002. doi: $10.3791 / 4002$

Wang, W. K., Chen, M. Y., Chuang, C. Y., Jeang, K. T., and Huang, L. M. (2000). Molecular biology of human immunodeficiency virus type 1. J. Microbiol. Immunol. Infect. $33,131-140$.

Wickham, L., Duchaine, T., Luo, M., Nabi, I. R., and Desgroseillers, L. (1999). Mammalian staufen is a double-stranded-RNAand tubulin-binding protein which localizes to the rough endoplasmic reticulum. Mol. Cell. Biol. 19, 2220-2230.

Wilhelm, J. E., and Vale, R. D. (1993). RNA on the move: the mRNA localization pathway. J. Cell Biol. 123, 269-274.
Xu, X., Song, Y., Li, Y., Chang, J., Zhang, H., and An, L. (2010). The tandem affinity purification method: an efficient system for protein complex purification and protein interaction identification. Protein Expr. Purif. 72, 149-156.

Yao, X. J., Mouland, A. J., Subbramanian, R. A., Forget, J., Rougeau, N. Bergeron, D., et al. (1998). Vpr stimulates viral expression and induces cell killing in human immunodeficiency virus type 1-infected dividing Jurkat $\mathrm{T}$ cells. J. Virol. 72, 4686-4693.

Yi, R., Bogerd, H. P., and Cullen, B. R. (2002). Recruitment of the Crm1 nuclear export factor is sufficient to induce cytoplasmic expression of incompletely spliced human immunodeficiency virus mRNAs. $J$. Virol. 76, 2036-2042.

Yisraeli, J. K. (2005). VICKZ proteins: a multi-talented family of regulatory RNA-binding proteins. Biol. Cell 97, 87-96.

Yoon, Y. J., and Mowry, K. L. (2004). Xenopus Staufen is a component of a ribonucleoprotein complex containing Vg1 RNA and kinesin. Development 131, 3035-3045.

Zaitseva, L., Cherepanov, P., Leyens, L., Wilson, S. J., Rasaiyaah, J., and Fassati, A. (2009). HIV-1 exploits importin 7 to maximize nuclear import of its DNA genome. Retrovirology 6,11 .

Zhang, Z., and Carmichael, G. G. (2001). The fate of dsRNA in the nucleus: a $\mathrm{p} 54(\mathrm{nrb})$-containing complex mediates the nuclear retention of promiscuously A-to-I edited RNAs. Cell 106, 465-475.

Zhao, C., Slevin, J. T., and Whiteheart, S. W. (2007). Cellular functions of NSF: not just SNAPs and SNAREs. FEBS Lett. 581, 2140-2149.

Zheng, Y. H., Plemenitas, A., Fielding, C. J., and Peterlin, B. M. (2003). Nef increases the synthesis of and transports cholesterol to lipid rafts and HIV-1 progeny virions. Proc. Natl. Acad. Sci. U.S.A. 100, 8460-8465.

Zhou, H., Xu, M., Huang, Q., Gates, A. T., Zhang, X. D., Castle, J. C. et al. (2008). Genome-scale RNAi screen for host factors required for HIV replication. Cell Host Microbe 4, 495-504.

Zimmerman, C., Klein, K. C., Kiser, P. K., Singh, A. R., Firestein, B. L., Riba, S. C., et al. (2002). Identification of a host protein essential for assembly of immature V-1 capsids. Nature $415,88-92$

Zolotukhin, A. S., Michalowski, D., Bear J., Smulevitch, S. V., Traish, A. M., 
Peng, R., et al. (2003). PSF acts through the human immunodeficiency virus type 1 mRNA instability elements to regulate virus expression. Mol. Cell. Biol. 23, 6618-6630.

Conflict of Interest Statement: The authors declare that the research was conducted in the absence of any commercial or financial relationships that could be construed as a potential conflict of interest.

Received: 31 July 2012; accepted: 27 September 2012; published online: 25 October 2012

Citation: Milev MP, Ravichandran $M$, Khan MF, Schriemer DC and Mouland
AJ (2012) Characterization of Staufen 1 ribonucleoproteins by mass spectrometry and biochemical analyses reveal the presence of diverse host proteins associated with human immunodeficiency virus type 1. Front. Microbio. 3:367. doi: 10.3389/fmicb.2012.00367

This article was submitted to Frontiers in Virology, a specialty of Frontiers in Microbiology.
Copyright (C) 2012 Milev, Ravichandran, Khan, Schriemer and Mouland. This is an open-access article distributed under the terms of the Creative Commons Attribution License, which permits use, distribution and reproduction in other forums, provided the original authors and source are credited and subject to any copyright notices concerning any third-party graphics etc. 